Revista de Estudios Histórico-Jurídicos

[Sección Historia del Derecho Europeo]

XXXI (Valparaíso, Chile, 2009)

[pp. 217 - 258]

\title{
POLICÍA DE VAGOS PARA LAS CIUDADES ESPAÑOLAS DEL SIGLO XVIII*
}

["Police for Vagabonds in Spanish Cities of the $18^{\text {th }}$ Century"]

\author{
ISABEL RAMOS VÁZQUEZ** \\ Universidad de Jaén
}

\section{RESUMEN}

En el siglo XVIII, se desarrolló una especial policía acerca de la mendicidad y la vagancia en toda Europa, y también en España. El gobierno mostró un particular interés sobre este tipo de gente, porque los autores de la Ilustración pensaban que eran uno de los principales obstáculos para lograr el progreso de la Nación. La idea era socorrer sólo a los verdaderos pobres en instituciones públicas, y hacer trabajar a los vagos u ociosos. Por ese motivo, la Monarquía comenzó a regular una cuestión que tradicionalmente había competido a las ciudades.

Palabras Clave: Siglo XVIII - Ilustración - Mendicidad - Vagancia, Administración pública, Ciudades.

\begin{abstract}
In the eighteenth century, a particular administration of begging and vagrancy was developed in all Europe, and also in Spain. The government showed a particular interest about this kind of people because the enlightened writers thought they were one of the main problems for the progress of the Nation. The idea was to assist only the real paupers in public institutions and make work the vagues or slakers. That's why the monarchy began to regulate a question that traditionally was concerned the municipalities.

Keywords: Eighteentn - Century - Enlightenment - Begging, - Vagrancy Public Administration - Municipalities.
\end{abstract}

* Este artículo forma parte del proyecto de investigación del Ministerio de Innovación, Ciencia y Tecnología de España: "Historias ciudadanas del Reino de Jaén. Manifestaciones y discursos de poder de las élites urbanas jiennenses (siglos XV-XVIII)", ref: HAR200804597/HIST.

** Dirección postal: Área de Historia del Derecho, Universidad de Jaén, Campus de La Lagunilla, s.n., Edificio D-3, 23021 Jaén, España. Correo electrónico: iramos@ujaen. es 


\section{INTRODUCCIÓN}

El problema de la asistencia, recogida o castigo de los pobres, vagos, ociosos, holgazanes, mendigos o mal entretenidos, que asolaban las ciudades de los reinos de España era antiguo. Tales sectores marginales de la población siempre habían existido, aunque comenzaron a convertirse en una cuestión especialmente preocupante para la comunidad política a partir de la crisis rural y el correlativo crecimiento urbano que se produjo ya durante la Baja Edad Media en algunos lugares europeos, y sobre todo en la Edad Moderna española, donde la crisis económica del siglo XVII elevó el problema de la vagancia y la ociosidad a índices verdaderamente alarmantes.

La literatura de la época, que frente a la crisis política y económica despuntó, no obstante, como la Edad de Oro de las letras españolas, es pródiga en la descripción de esas ciudades que parecían tomadas por los personajes marginales de los que tratamos, a los que se les relacionaba inmediatamente con la pequeña delincuencia o la criminalidad de márgenes: eran los pícaros, rufianes, engañifes, ladronzuelos o hurtadores. Baste recordar las obras pioneras del maestro Cervantes (Rinconete y Cortadillo es la más emblemática), Fernando de Rojas o Francisco Delicado, y más concretamente las novelas picarescas de Mateo Alemán, Luis Vélez de Guevara, Vicente Espinel o Francisco de Quevedo, entre otros, para hacerse una idea muy precisa del problema social al que nos referimos.

La cuestión era especialmente sensible en las grandes ciudades. Sin duda en Madrid, donde estaba la Corte, y en localidades populosas y costeras, con un importante comercio y tránsito de población, como Sevilla, Valencia o Barcelona. Aunque también afectaba a otras muchas poblaciones del reino, donde los mendigos u holgazanes comenzaban a amontonarse, buscando sobre todo en las puertas de las Iglesias, o en Hospitales y Obras Pías, el remedio a su situación a través de la caridad. De ella, la beneficencia o caridad cristiana, es de lo que habían vivido hasta entonces. Pero la sociedad moderna clamaba por nuevas soluciones.

Efectivamente, en la Edad Moderna se había producido ya un cambio de importancia con respecto a la consideración de la pobreza o la mendicidad. Si durante la Edad Media, a partir del pensamiento tomista que difundió con su propio ejemplo Santo Tomás, éstos habían sido valores relacionados con la resignación y austeridad que predicaba el Cristianismo ${ }^{1}$, en la Edad Moderna había pasado a convertirse en manifestaciones propias del vicio, la delincuencia y la depravación moral, que suponían un peligro para la sociedad y requerían la acción de las autoridades ${ }^{2}$.

De ser una cuestión privada, en beneficio tanto del pobre (que a través de la austeridad se entregaba a Dios y hallaba la salvación), como del rico o pudiente (que encontraba también en la caridad un medio de acercarse al cielo), la mendicidad se había convertido en un problema público. Los intereses sociales de la nueva

\footnotetext{
${ }^{1}$ López Alonso, C., La pobreza en la España medieval. Estudio Histórico-Social (Madrid, 1986).

${ }^{2}$ Como obra de conjunto para entender la evolución de la pobreza, véase CAPELLÁN DE Miguel, G., Enciclopedia del pauperismo (Cuenca, 2007), 5 vols.
} 
población urbana, la defensa de un nuevo valor de propiedad volcado cada vez más sobre los bienes materiales y fungibles, y no meramente sobre los inmuebles, y la difícil búsqueda de la paz social por parte de un poder público debilitado, para el que este sector de la población era un peligroso foco de conflictos, fueron, en consecuencia, los elementos que sin duda precipitaron el cambio de mentalidad con respecto a la pobreza. La comunidad pública o el nuevo concepto de "Estado", el bien común, si lo preferimos, se impuso así también en esta cuestión sobre la individualidad medieval.

Para ello se requirió una justificación moral y una nueva doctrina jurídica, y tanto la Teología como la ciencia del ius commune (que iban de la mano) coadyuvaron en esa dirección. Aunque hubo precedentes de importancia ${ }^{3}$, en general fueron las consignas establecidas por la Contrarreforma católica en el Concilio de Trento ${ }^{4}$, y también los pensadores humanistas del siglo XVI, los que difundieron por toda Europa una nueva visión de la pobreza, siguiendo las ideas desarrolladas principalmente por Juan Luis Vives a partir de criterios aprendidos de su maestro Erasmo de Rotterdam5.

La obra de Vives, De subventione pauperarum o Tratado del socorro de los pobres $^{6}$, sirvió de referente al resto de los tratadistas que se ocuparon de la cuestión en toda Europa, y planteaba la dualidad existente entre una pobreza "verdadera", de niños y hombres enfermos o ancianos que seguían mereciendo el cuidado de la sociedad a través de obras de caridad; y otra pobreza "fingida", de holgazanes o vagos que eran perfectamente válidos para trabajar y no podían seguir viviendo de la beneficencia. Tanto unos como otros requerían una nueva relación con la comunidad. Unos a través del control y la asistencia comunal en obras colectivas, y otros a través del castigo y el trabajo.

Comenzó a defenderse así la necesidad de buscar alguna ocupación o utilidad para que los pobres fingidos o vagos redundaran en beneficio de la sociedad. Lo que se proponía, en última instancia, en los muy remotos orígenes del sistema capitalista (en esta clave lo ven, entre otros, autores como Pasukanis, Melossi y Pavarini ${ }^{7}$ ), era conseguir algún rendimiento de los ex campesinos o jornaleros

\footnotetext{
${ }^{3}$ Los autores que se han acercado al tema coinciden en señalar que, en puridad, el cambio de planteamiento en cuanto a la mendicidad se produjo tras la Peste Negra que afectó a Inglaterra en 1349 y a Francia en 1350, y precisamente fue en estos países donde se desarrollaron las primeras experiencias capitalistas. Véase, por ejemplo, Soly, H., Pobreza y capitalismo en la Europa preindustrial (1350-1850) (Madrid, 1986).

${ }^{4}$ Jones, M., La Contrarreforma: Religión y sociedad en la Europa moderna (trad. cast., Madrid, Akal, 2003).

${ }^{5}$ Sobre esta particular cuestión, Susín BeLtrán, R., Los discursos sobre la pobreza. Siglos XVI-XVIII, en Cuadernos de Investigación Histórica Brocar 24 (2000), pp. 105-135.

${ }^{6}$ Vives, J. L., Tratado del socorro de los pobres (Brujas, 1526, trad. cast. de J. G. Nieto, Valencia, s. d.)

${ }^{7} \mathrm{El}$ análisis marxista/capitalista de la situación a la que nos referimos, nos lo ofrecen Pasukanis, E. B., Teoría general del derecho y el marxismo (Barcelona, 1976), Melossi, D. - PaVArini, M., Cárcel y fábrica. Los orígenes del sistema penitenciario (siglos XVI-XIX) (trad. cast. México, 1985); o PAVARINI, M., Control y dominación. Teorías criminológicas burguesas y proyecto hegemónico (Buenos Aires, 2003). En esta misma línea, atiéndase también a SuMMER, C., Marxism and deviancy theory, en The Sociology of Crime and Delinquency (The New Cri-
} 
que vagaban por toda Europa tras la crisis rural, buscando un doble objetivo: de un lado, evitar que pasaran a engrosar las filas de la delincuencia, como única salida a su situación; y de otro lado, procurar algún sistema por el que el mercado laboral fuera capaz de absorber el excedente de población activa y hacerla rentable en términos económicos.

Siguiendo estas consignas, más que para castigar a los mendigos útiles o capaces, como se venía haciendo en España, en distintos lugares de Europa comenzaron a proponerse nuevas soluciones, como las "Houses of Correction" o "Work.houses" de Inglaterra, las "Ras-puis" de Holanda, los "Hôpitaux générales" franceses o las "Zuchtäusern" de Alemania, para hacerlos trabajar". El trabajo era forzado, porque se partía de doblegar la voluntad del vago, delincuente potencial, y redundaba sólo en beneficio del poder público. Pero a través del encierro y el trabajo se pretendía también la corrección y educación del vago, que debía ser devuelto a la sociedad como un ciudadano trabajador y honrado.

En España, ya en el siglo XVI se hicieron eco de tan innovadoras ideas Miguel de Giginta y Cristóbal Pérez de Herrera. En 1575, el canónico Miguel de Giginta escribió un tratado para el rey Felipe II, en el que le proponía la creación de ciertas manufacturas reales de seda, lana y esparto en las que ocupar a los pobres detenidos en los hospicios ${ }^{9}$. Pero, a pesar de la buena acogida que tuvo la propuesta en los ambientes intelectuales y políticos, las dificultades económicas por las que atravesaba la monarquía impidieron que el proyecto pudiera llevarse a la práctica. Consciente de tales dificultades, unos años más tarde el Protomédico de las Galeras de su Majestad, Cristóbal Pérez de Herrera, propuso al rey que, si no podían construirse las citadas manufacturas, al menos se crearan unas Casas de Pobres destinadas a su reeducación o enmienda, de las que sólo pudieran salir los pobres verdaderos para mendigar durante el día, con licencia y una insignia al cuello ${ }^{10}$.

Tampoco esta propuesta pudo llevarse a cabo. Pero, aún así, las obras de Giginta y Pérez de Herrera nos han quedado como un fidedigno referente de que, al igual que en el resto de Europa, en España también estaba cambiando la visión de la pobreza. Para el pobre verdadero se seguía predicando la caridad, aunque de forma limitada y controlada por la comunidad. Mientas que para el pobre fingido o vago comenzaron a arbitrarse algunas sanciones, de las que se contaba con algún parco antecedente, a través del destierro, las galeras y fundamentalmente la cárcel.

La única voz discordante frente a las nuevas ideas fue la del teólogo tridentino Domingo de Soto. En el año 1540, una comisión presidida por el Cardenal Tavera, había establecido una serie de medidas para controlar la mendicidad en Castilla, prohibiendo por primera vez que los pobres salieran de sus tierras para

minologies) (New York, 1976); o TRINIDAD FERnÁndez, P., La defensa de la sociedad. Cárcely delincuencia en España (siglos XVIII-XX) (Madrid, 1991).

${ }^{8}$ Sobre estos establecimientos Trinidad Fernández, P., La defensa de la sociedad, cit (n. 7) p. 29.

${ }^{9}$ Giginta, M., Tractado del remedio de pobres (Coimbra, 1579).

${ }^{10}$ Pérez de Herrera, C., Discurso del Amparo de los legítimos pobres y reducción de los fingidos (Madrid. 1598; Madrid, Clásicos Castellanos, 1975). 
pedir limosna, y estableciendo la necesidad de vigilar si cumplían con los preceptos cristianos para permitirles mendigar. En defensa de estas medidas restrictivas de la mendicidad, aun cuando fuera verdadera, se pronunció en 1545 Juan de Medina en su tratado de Charidad discreta, que provocó la inmediata reacción de Domingo de Soto en una interesante polémica sobre la pobreza, en la que se oponían la visión tradicional a los nuevos postulados ideológicos.

En principio, Domingo de Soto se había pronunciado a favor de las disposiciones de 1540. Pero al comprobar la interpretación que se hacía de las mismas, se decidió a replicar a Juan de Medina exponiendo cuál era, a su parecer, el verdadero sentido de las normas. En su opinión, el Derecho tradicional a pedir limosna no podía ser coartado de ninguna manera, dejándose la asistencia en manos de organizaciones asistenciales que siempre serían parciales o artificiosas a la hora de prestar los auxilios. El fin de las disposiciones adoptadas era, para él, atender mejor a los pobres y no evitar la molestia que pudieran causar a otros ciudadanos, y consideraba absolutamente improcedente someter a los pobres a exámenes doctrinales, porque la caridad cristiana no podía someterse a condiciones ni restricciones ${ }^{11}$.

A pesar de ello, la tendencia que se impuso finalmente fue la que abogaba por la gestión pública de la pobreza, comenzándose a dictar ya algunas normas de policía de vagos durante los siglos XVI y XVII, entre las que se incluían medidas de control, restrictivas o limitativas, e incluso sancionadoras, según el caso. La competencia era esencialmente ciudadana. Los distintos concejos, a través de sus ordenanzas municipales, daban las normas a seguir en sus respectivos términos jurisdiccionales. Sin embargo, desde el gobierno central, los reyes Austria no dudaron en dictar también ciertas leyes de carácter general, destinadas en ocasiones a su mero cumplimiento en la ciudad de la Corte, o encaminadas a fijar las líneas comunes de acción.

Esta policía llegó a su punto más álgido con el advenimiento de la nueva dinastía Borbón en el siglo XVIII ${ }^{12}$. Los factores que la impulsaron entonces, convirtiéndola en un rasgo estructural de la administración borbónica, fueron de distinta índole. De un lado, hay que tener en cuenta la influencia francesa que los nuevos monarcas trajeron consigo, así como su necesidad coyuntural de mantener el orden público en una sociedad que había quedado muy debilitada y dividida por la Guerra de Sucesión. Para ello no sólo debían mantener un férreo control sobre los sectores de población que podían desatar las iras del pueblo, garantizando la seguridad de los ciudadanos, sino que también tenían que poner

${ }^{11}$ Soto, D., Deliberación en la causa de los pobres (Salamanca, 1545; edición de Martínez Casado, E., La causa de pobres, Salamanca, 2006).

${ }^{12}$ Véase, entre otros, Pérez Estévez, R., El problema de los vagos en la España del siglo XVIII (Madrid, 1976); SoubeYroux, J., El encuentro del pobre y la sociedad: asistencia y represión en el Madrid del siglo XVIII, en Estudios de Historia Social, 20-21 (1982); o CARASA SOTO, P., Pauperismo y Revolución burguesa. Burgos 1750-1900 (Valladolid, 1987); y EL MISMO, Los peligros de la pobreza. Los valores del liberalismo y las soluciones asistenciales burguesas, en Antiguo Régimen y liberalismo. Homenaje a Miguel Artola (Madrid, 1995), II. 
fin a los largos años de crisis económica que heredaban del siglo XVII, reactivando la economía.

El despegue de la economía dieciochesca, en el que se cifraba principalmente la felicidad del pueblo de la nueva ideología iluminista, centró nuevamente la atención sobre el problema de la población "baldía" o desocupada que holgazaneaba por los campos y las ciudades. Los ilustrados del Despotismo fomentaron sobre todo el estudio de la "economía política" para salir de las crisis y hallar la prosperidad de la Nación ${ }^{13}$, y uno de los desajustes que precisamente encontraron en ella fue el problema de la vagancia u ociosidad. Para procurar la prosperidad de una Nación, debían trabajar todos los hombres que hubiera en ella, sin excepciones, considerándose así por vez primera al ciudadano un activo del Estado: "La población se aumenta de diferentes modos físicos y politicos: se aumenta físicamente cuando se acrece el número de individuos, se aumenta politicamente cuando un hombre que no trabaja ni da utilidad alguna a la república se hace un vasallo útil inclinándole a la industria, y esto es el argumento que más importa, pues cuando se dice que la riqueza del soberano consiste en el número de sus vasallos, éste se debe entender de vasallos útiles solamente, porque un millón de holgazanes, vagabundos y mendigos de población, lejos de aprovechar, sirven de una carga muy pesada al Estado, sin los que estaría mucho mejor y más rico" 14 .

Desde esta perspectiva, se multiplicaron los estudios y propuestas acerca de los vagos, buscando su utilidad al servicio del Estado. No en vano, el primer tratado con el que se inicia el tomo I de la Biblioteca Española Económica-Política, realizada a finales de siglo por Sempere y Guarinos, trata concretamente de la Policía de España acerca de los pobres, vagos y malentretenidos ${ }^{15}$. Y, sin ánimo de ser exhaustiva, otros autores que se pronunciaron largamente sobre el tema fueron Bernardino Ward, Feijoo, Ustariz, Foronda, Meléndez Valdés, Aranda, Olavide, Cabarrús, Anzano, Forner, Jovellanos, Campomanes o Floridablanca.

Buscando una ocupación forzada a los vagos o malentretenidos, en servicio de la comunidad, se conseguía además otro objetivo fundamental: la defensa de un renovado valor de la propiedad en beneficio de la nueva clase en ascenso, la burguesía. En el siglo XVIII se habían multiplicado los delitos contra la propiedad. De una "criminalidad de sangre", propia de la época medieval, se había pasado durante la Edad Moderna a una mayoritaria criminalidad "de márgenes”, protagonizada precisamente por los personajes de los que tratamos, que robaban para

${ }^{13}$ Citando a Campomanes, Sempere y Guarinos, J., Biblioteca Española Económico-Política (Madrid, 1801), I, p. 8: "Meditando bien sobre las causas de nuestra decadencia, ninguna hay más cierta, y radical, que la ignorancia de la politica económica. 'Todas las Naciones - dice el Sr. Campomanes- han tenido sus eclipses, y decadencia. Debe atribuirse ésta comúnmente al poco aprecio de las obras políticas, y á la falta de cálculo, y reflexión en las causas originarias, que debilitan la industria, y la ocupación de la gente'. Es pues conveniente, y aún de absoluta necesidad, el fomentar, y propagar el estudio de la Economía politica, por todos los medios imaginables".

14 Ward, B., Proyecto económico (Madrid, 1762, ed. L. Castellano, Madrid, 1982), p. 79.

${ }^{15}$ Sempere y Guarinos, J., Policía de España acerca de los pobres, vagos y malentretenidos, en Biblioteca, cit. (n. 13), tomo I. 
vivir $^{16}$. Por eso, la acción del Estado, a través del Derecho, adquirió un incipiente tinte burgués en respuesta a las demandas de la nueva clase social detentadora de la riqueza.

Ello no hubiera sido posible sin el aumento de la eficacia administrativa del Estado que también se produjo, como factor precipitante del cambio, durante el siglo XVIII. La reorganización y reforzamiento de la estructura administrativa del Estado fue, sin duda, una prioridad de los Borbones, que no sólo centralizaron la administración para intervenir de forma más directa en su funcionamiento, sino que también la dotaron de mayores recursos materiales y personales al objeto de controlar a la población y prevenir cualquier fuente de excesos o transgresiones, reforzando sobre todo el aparato policial ${ }^{17}$.

Finalmente, otro elemento que precipitó el enorme movimiento contra la mendicidad y la pobreza en el siglo XVIII, fueron las constantes críticas de los ilustrados contra las formas de asistencia tradicional, que tenían que ver muy directamente con el discurso paternalista o tutelar que emprendió el Estado del Despotismo con respecto a los grupos más débiles o necesitados de la población. Era una obligación del Estado corregir y educar a los ciudadanos, velando por su felicidad; y a ello no se prestaban las antiguas formas de asistencia, basadas en la caridad y gestionadas por la iniciativa privada en su mayoría. Por eso, los pensadores iluministas emprendieron una denodada campaña para la eliminación de los antiguos hospitales, cofradías, obras pías o casas de misericordia de carácter privado, proponiendo la utilización de sus fondos, y otros públicos, para la construcción de unos nuevos "hospicios generales" orientados a la educación de la población y el aprendizaje de un oficio.

Teniendo en cuenta todas estas consideraciones, puede concluirse que la problemática que afectó a los pobres, vagos o malentretenidos durante el siglo XVIII, involucró a distintas disciplinas, desde las que se ha afrontado últimamente su estudio. Las más fecundas han resultado ser la historia social ${ }^{18}$, y la historia

${ }^{16}$ Sobre el advenimiento de la sociedad de masas y el cambio en el modelo de criminalidad en el siglo XVIII, véase NICÉFORO, A., La transformación del delito en la sociedad moderna (Madrid, 1902, trad. de C. Bernaldo de Quirós); Durkheim, E., Suicide. A Study in Sociology (s. 1., 1897, New York, 1951); FouCault, M., Vigilar y castigar (ed. Madrid, 1992), pp. 81-82; Alloza Aparicio, A., En busca de las causas del crimen. Teorías y estudios sobre delincuencia y justicia penal en la España Moderna, en Espacio, Tiempo y Forma, serie IV: Historia Moderna (2001), XIV, pp. 477-478 y 485-486; y, desde una perspectiva eminentemente documental, Palop Ramos, J. M., Delitos y penas en la España del siglo XVIII, en Estudis 22 (1996), pp. 65-97, donde se ofrecen datos de las Salas del Crimen de las Reales Audiencias, de algunos años de la década ochenta del siglo XVIII, en los que se comprueba el elevado índice de delitos "contra la propiedad" (robos y hurtos).

${ }^{17}$ Antón Mellón, J., Ordenamiento juridico burgués y cuestión social; y Recansens I Brunet, A., La burguesía y los orígenes del aparato policial, en Bergalli, R. - Mari, E., Historia ideológica del control social (Barcelona, 1989); GiménEz López, E., Militares en Valencia (17071808). Los instrumentos del poder borbónico entre la Nueva Planta y la crisis del Antiguo Régimen (Alicante, 1990); y Vallejo García-Hevia, J. M., Campomanes y la acción administrativa de la Corona (1762-1802) (Oviedo, 1998).

${ }^{18}$ Repárese en las obras ya citadas de Pérez Estévez, Soubeyroux, Carasa Soto o Capellán de Miguel, a las que se podrían añadir otras como la de Jiménez SAlas, M., Historia de las 
político-criminal ${ }^{19}$, aunque también pueden encontrarse interesantes aportaciones desde el punto de vista de la historia de la educación ${ }^{20}$, e incluso de la historia económica ${ }^{21}$. La perspectiva que aquí se plantea, sin obviar la riqueza que aportan estos estudios, pretende abundar, sin embargo, en otro aspecto de no menor trascendencia: la acción del Estado o gestión administrativa de la mendicidad, es decir, la policía de pobres y vagos que llevó a cabo el gobierno central en el siglo XVIII, reordenando y unificando la normativa adoptada por las distintas ciudades de la monarquía.

\section{ANTECEDENTES JURÍDICOS FRENTE AL PROBLEMA DE LA POBREZA Y LA MENDICIDAD}

Aunque en el momento más álgido de la policía de vagos, a finales del siglo XVIII, Juan Sempere y Guarinos retrotraía los antecedentes de este tipo de normas a las leyes dictadas por Graciano, Valentiniano y Teodosio, así como a antiguos cánones de la Iglesia sobre la mendicidad, apoyando con ello "la más pura disciplina" que se había restaurado en el Santo Concilio de Trento ${ }^{22}$, lo cierto es que las primeras leyes generales de policía o control de vagos de las que tenemos fehaciente noticia en el reino de Castilla son de mediados del siglo XIV, y, al margen de toda teología, estaban directamente relacionadas con la época de carestía o crisis económica por la que se atravesaba el reino.

Quizá las más tempranas fueron los distintos Ordenamientos de menestrales dados por Pedro I en las Cortes de Valladolid de 1351, en los que la principal causa a la que se atribuía la "muy grand mengua" del momento, era precisamente la gran cantidad de mendigos que no aportaban su trabajo para labrar los campos ${ }^{23}$. Por ello, se estableció como primera medida "que ningunos omes nin mugeres, que ssean et pertenescan para labrar, non anden baldios por el mio sennorio, nin pediendo nin mendigando; mas que todos lazren et viuan por labor dessus manos, ssaluo aquellos et aquellas que ouieren tales enfermedades et lissiones o tan grand vejez quelo non puedan ffazer, et moças menores de edat de doze annos".

La norma se reiteró posteriormente por Enrique II y Juan $\mathrm{I}^{24}$, añadiendo

asistencia social en la España Moderna (Madrid, 1958); o TRINIDAD, P., Asistencia y previsión social en el siglo XVIII, en AAVV, De la beneficencia al bienestar social: cuatro siglos de acción social (Madrid, 1986), pp. 89-90.

${ }^{19}$ Con obras como las ya citadas de Pasukanis, Melossi, Pavarini, Summer, Foucault, Soly, o Trinidad Fernández.

${ }^{20}$ Por ejemplo, Santolaria Sierra, F., Marginación y educación. Historia de la educación social en la España moderna y contemporánea (Barcelona, 1997).

${ }^{21}$ Perrotta, C., La disputa sobre los pobres en los siglos XVI y XVII: España entre desarrollo y regresión, en Cuadernos de Ciencias Económicas y Empresariales (1999).

${ }^{22}$ Véase: Sempere y Guarinos, J., Policía de España acerca de los pobres, vagos y malentretenidos, en Biblioteca, cit. (n. 13), I, pp. 41-47.

${ }^{23}$ Cortes de los Antiguos Reinos de León y Castilla [en adelante CLC.] (Madrid, 1863), II, pp. 75-124.

${ }^{24}$ Respectivamente en las Cortes de Toro de 1369 , pet. $31^{\mathrm{a}}$, y en las Cortes de Burgos de 1379, pet. 20, en CLC. (Madrid, 1863), II, pp. 173 y 294. 
este último a la única pena de azotes que se había prescrito para los infractores ${ }^{25}$, una segunda pena de destierro en las Cortes de Burgos de 1379 ("queles fagan dar çinquenta açotes e los echan fuera delos logares”). Ninguna de ellas produjo el resultado deseado y, haciendo gala de una enorme modernidad, en las Cortes de Bribiesca de 1387, Juan I volvió a pronunciarse sobre el tema, estableciendo como sanción para mendigos y holgazanes la posibilidad de obligarles a prestar un servicio militar durante "un mes sin soldada", sólo en cuyo defecto se debía recurrir a la pena de azotes y destierro: "Grand danno viene alos nuestros rengos por ser enellos consentidos o gouernados muchos vagabundos e folgazanes que podrían trabaiar e beuir de su afan e non lo fazen; los quales non tan sola mente biuen del sudor de otros ssyn lo trabaiar e merecer, mas aun dan mal enssyenplo alos otros queles veen fazer aquella vida, por lo qual dexan de trabaiar e tornan sse ala vida dellos, e por ende non sse pueden fallar labradores e fincan muchas heredades por labrar e vienen sse a hermar. Por ende nos por dar rremedio aestos dannos, ordenamos quelos que asy andudieren vagabundos e folgazanes que non quisieren afanar de ssus manos nin beuir con señor, que qualquier de nuestros regnos los pueda tomar por su abtoridat e seruirse dellos un mes sin ssoldada, saluo queles den comer e beuer. Essy alguno non los quisiere tomar asy, quelas justicias delos lugares den alos dichos uagabundose folgazanes ssesenta açotes e los echen dela villa. E islas justicias asy non lo fezieren, que pechen por cada uno delos dichos folgazanes sseys çientos $m r$. para la nuestra cámara, e los duzientos ssean para el acusador" ${ }^{26}$.

No pasaron de aquí los primeros intentos regios, y la policía general contra vagos quedó olvidada durante los años posteriores, de forma paralela a la superación de la crisis económica. No es que dejaran de existir los mendigos y ociosos, relacionados de forma cada vez más directa con la delincuencia (antes por la sociedad que por la propia teología y doctrina jurídica, como veremos), sino que dejó de existir un interés principal sobre ellos por parte de la monarquía. Buena muestra de ello es la desinteresada respuesta de Juan II (un lacónico "quelas leyes que sobre esto fablan se guarden e cumplan”), a la denuncia que se le planteó sobre la cuestión en las Cortes de Madrid de 1435; la cual, no obstante, tiene el doble significado de ser, por un lado, la única que se produjo en este sentido durante todo el siglo XV (el problema no era acuciante), y, por otro, la que introdujo por primera vez en el debate político la nueva consideración de la mendicidad de la que se ocuparían denodadamente, un siglo después, los teólogos y juristas: "Otrosi, muy alto sennor, sepa vuestra alteza que enlas çibdades e villas e logares de vuestros rengos e enlos sennorios dellos ay e andan muchos omes e mugeres valdios e vaga mundos lançandose con maliçia a pedir a Dios e a otros ofiçios miserables, con entençion de non trabajar nin afanar sus cuerpos a ningund ofiçio, seyendo omes $e$ mugeres para ello, et tales que si quisieren meter los cuerpos a afan e trabajo fallarian ofiçios que fiziesen e personas con quien biuiesen elos tomarian a soldada e en

\footnotetext{
${ }^{25}$ CLC. (Madrid, 1863), II, p. 88: "Otrossi tengo por bien et mando que todos los omes et mugeres baldios que andodieren pediendo o mendigando [...] quel den por la primera vegada veynte açotes, et por la segunda vegada quarenta açotes, et por la terçera vegada sesenta açotes públicamente".

${ }^{26}$ Cortes de Bribiesca de 1387, pet. 5a, en CLC. (Madrid, 1863), II, pp. 370-371.
} 
otra manera, e les darian mantenimientos e las otras cosas queles fuesen menester, e las gentes se podrian seruir dellos e ayudarian a labrar e guardar ganados e fazer otras cosas e ofiçios e que podrian aprovechar al pueblo, e ellos non andarian valdios commo andan nin comerian su pan folgando. Por ende suplicamos sennor a vuestra alteza, quele plega de ordenar e mandar que de aqui adelante en alguna nin algunas çibdades e villas e logares delos vuestros rengos e sennorios non sean osados de estar nin esten nin anden omes nin mugeres vaga mundos a demandar limosnas nin otras cosas semejantes, saluo aquellos que fueren tan viejos e de tal dispusiçion o tocados de algunas dolencias o enfermedades que conosçida mente paresca por su aspecto que non son omes nin mugeres que por sus cuerpos puedan trabajar en ningunos nin algunos ofiçios de que se puedan proveer nin mantener" 27 .

Durante el siglo XV la cuestión de la creciente mendicidad no preocupaba tanto a los reyes, que habían emprendido la superación de la crisis económica con un vigor extraordinario (sobre todo a partir de la unión política de Castilla y Aragón, el final de la Reconquista y el Descubrimiento), como a los pueblos, que eran los que sufrían en la práctica el acoso cada vez mayor de los mendigos por sus calles e iglesias. Es por ello que, en esta época, serían los propios poderes municipales, a través de sus ordenanzas, los que se ocuparían fundamentalmente del problema de la vagancia. Y así, cada ciudad estableció sus propias normas de policía de vagos, dependiendo del número de ellos, las molestias de los vecinos, las propuestas recibidas, e incluso la propia sensibilidad de las autoridades locales con respecto al tema.

Coincide el momento histórico con la época de mayor esplendor del Derecho ordenancista municipal que, justificado ya doctrinalmente y amparado por el poder monárquico del que emanaba, sufrió un importante proceso de crecimiento y consolidación durante los siglos XV y XVI ${ }^{28}$. Las "ordenanzas" municipales, que superaron a los antiguos Fueros, la mayoría obsoletos, trataban de todos los asuntos de gestión ciudadana, y entre ellos de las labores de control y asistencia de pobres. Las soluciones eran dispares, dependiendo de la magnitud del problema en cada ciudad. Las ciudades más grandes, como Madrid, Valencia, Sevilla o Toledo, en las que la mendicidad estaba alcanzando niveles preocupantes, se dotaron de las normas más severas, incluidas las mutilaciones (en Toledo se les sancionaba con el corte de orejas ${ }^{29}$ ) y la pena de muerte en el caso de los reincidentes. Mientras que otras ciudades de menor tamaño, o con una menor afluencia de vagantes, se

${ }^{27}$ Cortes de Madrid de 1435, pet. 38a, en CLC. (Madrid, 1866), III, p. 236.

${ }^{28}$ Entre otros, EMBID IRUjo, A., Ordenanzas y reglamentos municipales en el Derecho español (Madrid, 1978); Ladero Quesada, M.A., Las ordenanzas locales (siglos XIII-XVIII), en En la España Medieval 21 (1998); Corral García, E., Ordenanzas de los concejos castellanos: formación, contenido y manifestación. Siglos XIII-XVIII (Burgos, 1988); Bernardo Ares, M., Las Ordenanzas municipales y la formación del Estado Moderno, en Axerquí. Revista de Estudios Cordobeses 6 (1983), en En la España medieval 3 (1987), y en El Poder Municipal y la Organización Política de la Sociedad (Córdoba, 1998); o Franco Silva, A., Estudios sobre ordenanzas municipales (siglos XIV-XVI) (Cádiz, 1999).

${ }^{29}$ Martín Gamero, A., Ordenanzas para el buen régimen y gobierno de la muy noble, muy leal e imperial ciudad de Toledo (Madrid, 1998, recurso electrónico, Fundación Histórica Tavera). 
decantaron simplemente por penas de azotes o destierro, o bien por establecer normas reguladoras, prescribiendo dónde y cómo se podía pedir, y establecimiento de las primeras licencias municipales para postular.

En términos generales, para los ociosos y vagabundos se impusieron durante el siglo XV las penas subsidiarias de azotes y destierro (los Reyes Católicos ordenaron, por ejemplo, el destierro de todos los "vagamundos" de la Corte), relegándose al olvido el servicio personal de un mes en el ejército que había ordenado Juan I, y que probablemente no llegó a tener aplicación práctica ${ }^{30}$.

Ahora bien, cuando el siglo XVI puso de relieve la necesidad de recursos personales que tenía la monarquía para mover la flota, los reyes Juana y Carlos I no dudaron en "acrecentar" la pena de los holgazanes o vagabundos, recuperando la antigua idea del trabajo o servicio personal para la monarquía, que se impuso junto a los azotes como una especie de destierro agravado a través de la pena de galeras: "De aqui adelante la dicha pena sea à que sirvan por la primera vez en las nuestras galeras quatro años, y sea traído a la verguença públicamente, seyendo el tal vagamundo mayor de veynte años: y por la segunda vez le sean dados cien açotes, y sirua en las nuestras galeras ocho años: y por la tercera vez le sean dados cien açotes, y sirva perpetuamente en las dichas galeras" ${ }^{31}$.

Para entonces, las ideas de Juan Luis Vives sobre la pobreza real y fingida, así como las nuevas consideraciones acerca de los pobres predicadas por el Concilio de Trento, que no hacían sino dar respuesta a una antigua demanda social, ya se habían extendido por los ambientes intelectuales y cortesanos, dando a los monarcas la justificación y las pautas de su actuación para una nueva policía general de vagos. En atención a ellas, se realizó el ordenamiento dado por primera vez en las Cortes de Valladolid de 1525 por doña Juana y Carlos I, que fue recogido en la Nueva Recopilación y reiterado en Cortes posteriores del siglo XVI, acerca de los llamados pobres "verdaderos" 32 .

En él, sólo fueron considerados mendigos "verdaderos" los menores de edad, los viejos y los enfermos o tullidos, y para controlarlos se obligó a las autoridades municipales, civiles y eclesiásticas a realizar las pertinentes labores de fiscalización, otorgando las licencias o cédulas para mendigar. A las justicias ordinarias locales les correspondía comprobar la veracidad de la pobreza y la determinación de la naturaleza del mendigo, pudiendo sólo excepcionalmente dar licencias para que pudiera pedir o ingresar en algún hospital fuera de su tierra o vecindad (por ejemplo, cuando en su ciudad se hubiera declarado una situación de peste o hambruna, o cuando algún pobre enfermaba en algún lugar del que no fuera vecino ni morador, siempre por tiempo tasado). Al margen de estos casos señalados, al mendigo sólo se le permitía pedir limosna en la ciudad o villa de la que fuera natural, y dentro de las seis leguas circundantes.

Los párrocos de las distintas parroquias o colaciones, eran los encargados de

${ }^{30}$ Nueva Rec. 8,11,1-3.

${ }^{31}$ Véase la pragmática de 25 de noviembre de 1522 en la Nueva Rec. 8,11,6. La medida fue reiterada por Felipe II en 1566, suprimiendo la necesidad del pregón ante de las detenciones y aumentando notablemente el concepto de holgazanes o vagabundos, en N. R. 8, 11, 11.

${ }^{32}$ Véanse Nueva Rec. 1,12,6-10, y Nov. Rec. 7,39,1-13. 
dar tales licencias a los pobres de sus barrios, comprobando previamente que habían cumplido las obligaciones morales de un buen cristiano confesando y comulgando (recordemos que si las licencias fueron rechazadas individualmente por el teólogo Domingo de Soto, aún lo fue más esta obligación moral, a pesar de lo cual se impuso en la letra de la ley). Las licencias se daban por un año, de Pascua de Resurrección a Pascua de Resurrección, aunque en el ínterin podían darse algunas otras en casos concretos, limitándolas hasta la citada fecha. Las penas para el mendigo que incumpliera estas disposiciones, o que utilizara licencias falsas o no propias, eran "que por la primera vez esté quatro días en la cárcel, y por la segunda ocho, y sea desterrado por dos meses; y por la tercera, le sea dada la pena de los vagamundos". La distinción entre unos y otros ya se había hecho ley.

Llama la atención, finalmente, dentro del grupo de leyes que comentamos, aquella con la que se culminó su redacción en la Nueva Recopilación, que abogaba por la enseñanza y la corrección de los menores como el mejor remedio para acabar con la mendicidad: "Porque de traer los padres, y madres sus hijos à pedir limosna, se amuestran à ser vagamundos, y no aprenden oficios: ninguna persona que pidiere por Dios en la forma susodicha, pueda traer, ni trayga consigo hijo suyo, ni de otro, que fuere de mas edad de cinco años: y siendo desta edad, y antes si ser pudiere, les pongan con personas à quien sirvan; y teniendo edad para ello, les enseñen oficio en que se puedan sustentar. Y encargamos á los Prelados, y juezes Eclesiásticos: y mandamos á las nuestras justicias, y à los Concejos, y à las Ciudades, y villas, que tengan mucho cuidado de dar alguna buena orden como los dichos niños, siruan á algunas personas, à aprendan oficios, como dicho es, y entretanto sean alimentados, sin que anden à pedir limosna" ${ }^{\prime 3}$.

La competencia, como se ve, era esencialmente ciudadana. Los monarcas sólo dotaron al reino del marco general o política común, y fueron los propios municipios los que desarrollaron en esta época, en atención al mismo, sus respectivas policías de mendigos o vagos, que en algunos lugares mejoraron mucho a partir de las consignas dadas en Cortes. Las facultades acerca del control de la pobreza y vagancia se sumaron así a los Capítulos de Corregidores ${ }^{34}$, dejándose simplemente la solución del problema en manos de estos oficiales. Pero como su acción era notoriamente insuficiente, ocupados, como estaban, con muchas otras labores de gobierno, y la mendicidad no dejaba de aumentar en las ciudades, en el año 1555 las Cortes comenzaron a pedir al monarca que en todos los pueblos se creara un "padre de pobres", dedicado exclusivamente a su cuidado. La figura nunca llegó a institucionalizarse tal y como se sugería, aunque probablemente inspiró a Felipe II la creación de los llamados "diputados de pobres" en $1565^{35}$.

Los diputados de pobres eran "dos buenas personas" que se habían de elegir en cada parroquia de cada villa o ciudad, para ayudar al párroco en las labores de información, examen, control y determinación de pobres, señalando cuáles eran verdaderos y cuáles fingidos. Su función esencial era recorrer los hospitales, posadas, plazas y otros lugares donde solían recogerse los vagantes, y determinar

\footnotetext{
${ }^{33}$ Nueva Rec. 1, 12, 11.

${ }^{34}$ Cortes de Madrid de 1528, pet. 45a, en CLC. (Madrid, 1882), IV, p. 469.

${ }^{35}$ Nueva Rec. 1, 12, 26.
} 
el grado de su pobreza, creando unos listados o memorias a partir de los cuales los párrocos y justicias podían otorgar las licencias preceptivas o castigar a los ociosos. Al margen de esta novedad, en estas leyes se reiteraron básicamente todas las disposiciones anteriores, prescribiéndose un especial cuidado en la forma de hacer las licencias (que en ellas se pongan características del pobre como la edad, color, estatura o alguna señal que lo defina para evitar el fraude), y ordenando a las Justicias y Concejos ciudadanos que se asegurasen de que hubiera al menos un hospital en su jurisdicción para recoger a los enfermos (éstos, por lo general, eran de carácter privado y se pagaban con los fondos de la caridad).

Desde el punto de vista doctrinal, como antes se ha dicho, fray Juan de Medina escribió en esta época su obra De la órden que en algunos pueblos de España se ha puesto en la limosna, para el remedio de los verdaderos pobres, publicada en Salamanca, en $1545^{36}$, para apoyar las nuevas ideas, y más adelante presentarían sus innovadoras aunque frustradas propuestas Miguel de Giginta y Pérez de Herrera. Pero en la práctica se avanzó poco más y, en palabras de Sempere, "si la mendicidad no habia podido desarraigarse en los gloriosos, y brillantísimos reynados de Carlos Vy Felipe II, reynados de continuos triunfos, conquistas y dilataciones de la monarquía española, ¿qué podría esperarse en el siglo XVII, siglo de continuas pérdidas de plazas, y provincias, de despoblación, y miseria, y de ruina de las artes, comercio, y agricultura?" 37 .

Ante la ineficacia del Derecho y las instituciones públicas, la sociedad del siglo XVII respondió de la única forma que sabía: a través de la caridad. Se multiplicaron los hospicios, hospitales, casas de misericordia, casas de arrepentidas, casas de expósitos o huérfanos, etc. Aunque algunos recibían fondos públicos, en su mayoría estaban financiados por capital privado a través de las iglesias, monasterios, conventos o cofradías. La reclusión que en ellos se hacía de los pobres verdaderos, ancianos, enfermos, mujeres o niños, no era coactiva, sino una simple medida asistencial o de socorro. Pero a veces el encierro era obligado, y los internos se veían sometidos a una obsesiva vigilancia y control con la intención de procurar su educación, enmienda o mejora.

Los niños debían aprender algún oficio para integrarse en el futuro como miembros honrados de la comunidad ${ }^{38}$. A las mujeres "de mala vida" se les imponían diversos trabajos y el aprendizaje de labores, a cambio de su sustento y moralización, procurándose también para algunas de ellas una dote con la que formar un honrado matrimonio ${ }^{39}$. E incluso los enfermos y dementes eran obligados en

${ }^{36}$ Es más conocida la segunda edición y siguientes de esta obra, bajo el renovado título de Caridad discreta practicada con los mendigos, y utilidades que logra la República en su recogimiento (Valladolid, 1757).

${ }^{37}$ Sempere y Guarinos, J., Policía de España acerca de los pobres, vagos y malentretenidos, en Biblioteca, cit. (n. 13), I, pp. 87-88.

${ }^{38}$ Véase: Álvarez Santalo, L. C., La Casa de Expósitos de Sevilla en el siglo XVII (Madrid, 1977); o Gómez Ruiz, T., El Hospital Real de Santa María Magdalena y la Casa de Expósitos de Almería (Almería, 1997).

${ }^{39}$ Véase: Vidal Gavidia, M. A., La Casa de Arrepentidas de Valencia (Valencia, 2001); o Ramos VÁzQuez, I., De meretricia turpidine. Una visión jurídica de la prostitución en la Edad Moderna castellana (Málaga, 2005), pp. 175 ss. 
ocasiones a trabajar para procurar alguna utilidad a quienes les mantenían ${ }^{40}$.

Sin embargo, el sistema no funcionaba, porque ni los niños dejaban de ser futuros ladronzuelos o delincuentes, ni las mujeres soportaban la austeridad que se les ofrecía en los lugares de recogida, ni los ancianos o enfermos encontraba en los hospitales la asistencia que requerían. Además, a pesar de los proyectos y debates que se sucedían sobre el adecuado funcionamiento de estos espacios, lo cierto es que en la práctica no se impuso, salvo excepciones, la separación o encierros individualizados que hubieran sido necesarios para aplicar medidas de corrección, más allá de una asfixiante disciplina, y en los mismos lugares se mezclaban los viejos, enfermos, locos o dementes, militares convalecientes, e incluso, a veces, en simples habitaciones separadas, mujeres desamparadas, enfermas o paridoras.

A pesar de ello, y ante la inexistencia de industrias o manufacturas en las que ocupar a los pobres, como clamaban los teóricos, estos establecimientos asistenciales de carácter privado fueron la única respuesta contra la ya incontrolable "pordiosería", junto con medidas sancionadoras para los pobres falsos o "argotes", como la pena de destierro, pero fundamentalmente la pena de galeras y cada vez más la pena de cárcel, que empezaba a perfilarse como una nueva sanción para este tipo de delincuentes menores ${ }^{41}$.

\section{DOCTRINA Y LEY EN EL SIGLO XVIII: LAS PRIMERAS REFORMAS EN LA POLICÍA DE VAGOS}

Los cambios frente a la realidad descrita comenzaron a producirse en el siglo XVIII, cuando, como se ha justificado bajo el epígrafe introductorio, los nuevos monarcas de la dinastía Borbón afrontaron una decidida y novedosa policía de vagos por diversas causas. Para los ilustrados dieciochescos la pobreza, el nomadismo y la ociosidad eran un problema angular de la sociedad que era necesario superar, a toda costa, para salir de la crisis económica, y lograr el buen gobierno y la paz social. Para ellos existían fundamentalmente tres motivos que aconsejaban luchar con firmeza contra la vagancia: que era una lacra para la economía e impedía prosperar a la Nación en la búsqueda de la felicidad común (economía política); que era el origen de la toda la depravación moral (paternalismo o tutela social de Estado); y que generalmente conducía al crimen y al engaño como forma de vida (seguridad pública). "Los males que suelen acarrear el desamparo y la pobreza"42 eran muchos, pues no solamente apartaban a la población del

${ }^{40}$ Véase: Galdiano y Croy, L., Breve tratado de los hospitales y casas de recogimiento desta Corte (Madrid, 1677); o Bermúdez de Pedraza, Hospital Real de la Corte (Madrid, 1645). Y de entre la bibliografía más actual: Foucault, M., Historia de la locura (México, 1979), I, cap. 2o; Soly, H., cit. (n. 3); o Roldán Barbero, H., Historia de la prisión en Espanya (Barcelona, 1988), pp. 36 ss,

${ }^{41}$ Sobre la creciente utilización de la cárcel para mantener a los ociosos, repárese en la orden dada por Carlos II en 1692, en Nueva Rec. 8,11, auto 6: "A los vagamundos, que se prendieren en esta Corte, se les asista todos los dias, que estuvieren en las cárceles, con un real de vellón al día del caudal de servicio de lanzas, dando orden al Depositario General de dicho caudal".

${ }^{42}$ Son palabras de Jovellanos, G. M., Discurso que pronunció en la Sociedad Económica de Madrid en 24 de diciembre de 1784, en Obras (Madrid, BAE, 1952), II, p. 29, que continúan: 
trabajo y la sociedad, ocasionando un significativo coste económico y político al Estado, sino que también daban lugar al crecimiento de todos los vicios (juego, alcohol, riñas, rufianismo, prostitución...), y especialmente a los delitos contra la propiedad, por la absoluta falta de respeto a este valor que tenían los pobres debido a su desarraigo. El nomadismo o desapego de los mendigos u holgazanes era entendido, por lo demás, como una seria amenaza para el Estado por parte de sus ideólogos, puesto que cualquier grupo incontrolado, sin residencia fija ni vínculos de dependencia, podía resultar subversivo o dañino. Los vagos no respetaban la propiedad ni la autoridad, y no tenían motivos para hacerlo porque carecían de todo y no tenían nada que perder. Y eso era peligroso.

Además, los holgazanes originaban un problema demográfico para el Estado puesto que, al "reproducirse como conejos" aumentaban la pobreza y sus problemas, contagiaban enfermedades "vergonzosas", y amenazaban la moral puritana de la burguesía. En este sentido, los ilustrados no sólo señalaban la transgresión moral y el vicio de los pobres, sino también la indiferencia que sentían ante la imagen urbana, ya que "para estimular la caridad ajena exageraban su aspecto desagradable, simulaban heridas o enfermedades, exponían o hasta alquilaban niños en deplorable estado"; todo lo cual molestaba mucho a la nueva sociedad dieciochesca ${ }^{43}$ : "Sin patria, sin residencia fija, sin consideración ni miramiento alguno, sin freno de ninguna autoridad, mudando de domicilio según su antojo, y en la más completa libertad, o más bien insubordinación e independencia, ni son vecinos de pueblo alguno, ni súbditos de ninguna autoridad, ni profesan la religión sino en el nombre, ni conocen párroco propio que los instruya en ella, ni nunca, en fin, se los verá en un templo oyendo una misa, ni en una devoción. Su vida miserable y vaga los exime de todo. Dados al vino y a un asqueroso desaseo, y durmiendo en parajes y cuadras, mezclados y revueltos unos con otros, no conocen la honestidad ni la decencia, y, borradas del todo las santas impresiones del pudor, se dan sin reparo a los desórdenes más feos. De este estado de entera independencia y envilecimiento nacen precisamente la degradación del alma y el abandono brutal con que se entregan a todos los vicios. De la mendiguez a la ratería y el robo no hay sino sólo un paso" 44 .

Junto a esta clase de justificaciones, que, como hemos dicho, atendían sobre todo al mantenimiento del orden público, la lucha contra la criminalidad, y la preservación de la moral y la virtud, los pensadores iluministas afrontaron decididamente el problema de la vagancia desde una segunda perspectiva de no menor trascendencia: "la economía política". A ella les había llevado la necesidad de salir a toda costa de la terrible crisis económica del siglo precedente, y en general con-

"la libertad inseparable de su misma indigencia; la necesidad de buscar socorros en un camino sembrado de lazos y peligros; la ociosidad, la desnudez, el desamparo, y sobre todo, la fuerza del mal ejemplo, auxiliada de los atractivos del lujo, los arrastran violentamente á la corrupción".

${ }^{43}$ Véase: Carasa Soto, P., Los peligros, cit. (n. 12), pp. 424-433.

${ }^{44}$ Meléndez Valdés, J., Discursos forenses, en Obras Completas (Madrid, Biblioteca Castro, 1997), III, p. 276, en Fragmentos de un discurso sobre la mendiguez, bajo la rúbrica “Corrupción moral y embrutecimiento de los mendigos". En pp. 277-280 se pronuncia sobre "La mendiguez reprobada por la religión, la moral y las leyes: los que la favorecen, malos ciudadanos", y en pp. 280-283 sobre Enfermedades de la mendiguez, y riesgo inminente de contagios en que por ella estamos. 
sistía en fijar las líneas estratégicas para superar todas las trabas que bloqueaban la producción y el progreso del Estado. Entre ellas, pronto se configuró como una línea básica o estructural la necesidad de utilizar la enorme masa de población inútil o "baldía" que holgazaneaba por las distintas ciudades del reino al servicio del Estado: "Siendo los hombres el fondo más precioso de las Monarquías, no disfrutarlos es la omisión más perjudicial y más culpable que puede padecer el Estado" 45.

En palabras del profesor Vallejo, "los escritores que se preocupan de este asunto a los largo de la centuria, especialmente en su segunda mitad [...], sueñan con transformar las muchedumbres de pordioseros en vasallos laboriosos, disciplinados y virtuosos" 46 . Desde que "nació un nuevo manantial de propiedad, mucho más copioso, y fructifero que la misma tierra: la industria, y el trabajo", no entendían que ningún hombre sano y en edad de trabajar dejara de aportar su fuerza, coadyuvando a su propia felicidad y el progreso del Estado. El trabajo en el campo, el oficio artesanal y cualquier otro que sólo dependiera de la fuerza o voluntad de la persona, eran campos de los que todo hombre podía y debía aprovecharse. En caso contrario se convertía en vago: "En tal estado, solamente deben reputarse por verdaderos pobres los niños, enfermos, y los que no teniendo asegurada la subsistencia, están imposibilitados de trabajar. Los mendigos robustos, y no comprehendidos en las clases indicadas, lejos de excitar la piedad, y conmiseración, deben ser perseguidos, y castigados, como escandalosos holgazanes, vagos y delinqüentes" ${ }^{\prime 7}$.

Resulta, en este sentido, especialmente esclarecedora la respuesta fiscal sobre vagos dada por Campomanes en 1764, en la que se recogieron los argumentos aducidos desde tiempo atrás por los pioneros de esta ciencia económico-política, que él retrotraía incluso hasta la obra de Pérez de Herrera: "Todo el contexto de esta Obra se encamina a demostrar la utilidad, que el Estado puede sacar, y señaladamente la Milicia, y Marina y Obras públicas, del gran número de Individuos de esta clase, que vagan y mendigan, sin querer aplicarse al trabajo del campo, ni a los oficios" ${ }^{38}$.

Continuaba su respuesta Campomanes en términos puramente económicos, calculando el número aproximado de vagos que había al momento en la Monarquía, unos 170.000, de los cuales, "quando se reputen entre niños y enfermos, inhábiles para el trabajo, treinta mil, quedan ciento y quarenta mil Valdios holgazanes de ambos sexos [...], cuya suma sería suficiente para mantener un Egército de Tierra formidable", y si se dedicaran a trabajar en la agricultura o en otros oficios mecánicos, considerando como mínimo "que al día podrían ganar una peseta, que haría otros ciento ochenta y dos millones y medio de reales, a beneficio de la riqueza nacional; con los quales podrían mantenerse a si, y a sus hijos, sin gravar al Estado, y este recibiría el aumento de los productos, que rendiría necesariamente la maniobra de las ciento y quarenta mil personas empleadas, que oy son holgazanes voluntarios, de depravadas costumbres".

${ }^{45}$ Ward, B., Obra Pía. Medio de remediar la miseria de la gente pobre de España, en Proyecto, cit. (n. 14), p. 196.

${ }^{46}$ Vallejo García-Hevia, J. M., cit. (n. 17).

${ }^{47}$ Sempere y Guarinos, J., Policía, cit. (n. 15), p. 7.

${ }^{48}$ Publicada por Coronas GonzÁlez, S., Ilustración y derecho. Los fiscales del Consejo de Castilla en el siglo XVIII (Madrid, 1992), p. 327. 
Abundando en la cuestión, aún se contemplaba un mayor beneficio, porque "si se considerase también la facilidad que tendría el Egército de reclutarse con personas, que no hiciesen falta en el Estado y la utilidad de los Labradores y Artesanos, aplicados en evitar a sus hijos, por este medio, en gran parte el perjuicio de abandonar la labranza, y los oficios, por causa del Servicio Militar, sería otra doble ganancia a favor de la Nación, porque esta gente honrada quedaría tranquila en el campo, y en los oficios, puesto que el Vago, por virtud de una Ley bien meditada, y egecutada, sería obligado a suplirle en el Egército" ${ }^{\prime 9}$.

Campomanes planteaba principalmente el destino en el ejército para los vagos fingidos u holgazanes, siguiendo la misma dirección que, no en vano, habían apuntado los Borbones desde su llegada al trono español, a principios del siglo XVIII. Entonces, como se ha dicho, comenzaron a afrontarse las reformas más serias con respecto al tema de la vagancia, $y$, habida cuenta que la pena de galeras, antes prescrita, había quedado obsoleta por el desarrollo de las nuevas técnicas navales, Felipe $\mathrm{V}$ decidió sustituirla por un servicio en las milicias que redundaría mayor utilidad a la monarquía.

La medida, amparada en leyes anteriores, comenzó a ordenarse ejecutar directamente a los oficiales competentes, intendentes y corregidores, a partir del año 1717 , pero fue en 1733 cuando se plasmó nuevamente en la letra de la ley, al objeto de que "se acuerde este asunto á las Justicias de estos reynos por la desidia con que hasta aqui se ha tratado, á fin de que vigilen con la mayor exactitud sobre su mas puntual observancia". Entonces, se ordenó expresamente que se apresara en adelante a todos los vagos y holgazanes del reino, y "los que fueren hábiles, $i$ de edad competente para el manejo de las armas, se pongan en custodia, para que, dándome cuenta, los mande destinar a los Regimientos, que sea conveniente" 50 .

Esta ley, sin embargo, no se cumplía con todo el rigor que precisaba, a pesar de los continuos requerimientos y mandamientos enviados para ello por el rey a las ciudades, y al poco tiempo de dictarse se llegó a la conclusión de que las justicias ordinarias de cada lugar no podían hacerse cargo de la misma, por tener que atender a otros muchos quehaceres, y cuando lo hacían se encontraban con demasiadas trabas procesales o forenses que les impedían llevar a buen término el procedimiento. Para dar respuesta a ambas cuestiones, se dictó la Real Ordenanza de Vagos de 1745, que, por un lado, pretendía centralizar la policía de vagos en la figura del Gobernador del Consejo, para que coordinase las medidas ejecutivas; y, por otro lado, autorizaba tanto a éste y sus tenientes, como a las justicias ordinarias, a proceder sumariamente, sin intervención de los tribunales superiores, en estos casos ${ }^{51}$.

${ }^{49}$ Coronas González, S., Ilustración, cit. (n. 48), pp. 328-329.

${ }^{50}$ Véanse Nueva Rec. 8, 11, auto 12 y auto 18, también en Nov. Rec. 12,31,6. Y en cuanto a las órdenes anteriores de apresamiento, Coronas GonzÁlez, S., El libro de las leyes del siglo XVIII (Madrid, 1996), 5 vols., tomo I, libro II, n. 24, p. 215, así como las notas 2 y 3 a Nov. Rec. 12,31,6.

${ }^{51} \mathrm{La}$ Real Ordenanza de vagos de 30 de abril de 1745, no fue recopilada en su integridad como derecho general del reino, pero se recoge gran parte de ella en la Nov. Rec. 12,31,7, nota 6 . 
La misma ordenanza previó también la creación de una "Secretaría de levas", que dirigiría el Gobernador del Consejo, para que, tras los juicios especiales y sumarísimos que se hicieran a los vagos, pudiera procederse de forma aún más rápida a su castigo al servicio en el ejército. El inspirador de este proyecto fue el Marqués de Ensenada, que entonces estaba encargado, entre otras, de la Secretaría del Despacho de Guerra, y había iniciado una importante política de fortalecimiento del Ejército y la Marina en previsión del inevitable conflicto que, a la larga, tendría que sostener España con Inglaterra por sus intereses coloniales. Para ello, contaba como pieza fundamental con los vagos y malentretenidos ${ }^{52}$. Pero su proyecto quedó frustrado por los numerosos inconvenientes que no tardaron en señalarse (por ejemplo, el riesgo de otorgar una autoridad ilimitada a los jueces ordinarios en los asuntos de vagos, la escasa colaboración que se podía presumir de otras jurisdicciones desplazadas, o las dificultades materiales para el recogimiento y mantenimiento de los vagos ${ }^{53}$ ), y finalmente la Ordenanza de vagos de 1845 fue ordenada recoger al poco tiempo de haberse publicado, sin que ni la Secretaría de levas, ni la autonomía jurisdiccional, pudiesen llevarse a la práctica ${ }^{54}$.

A pesar de ello, la influencia de la Ordenanza de vagos de 1745 fue decisiva tanto en la metrópoli como en las colonias ${ }^{55}$, y podría afirmarse que con ella se inauguró la nueva campaña contra los vagos y ociosos que se extendería con un vigor inusitado durante todo el siglo XVIII. No consiguió la centralización administrativa del problema, pero persistieron muchas otras de sus disposiciones, como, por ejemplo, la que ordenaba una renovada y audaz persecución de los holgazanes para el servicio en el ejército, y las que, por primera vez en la legislación española, concretaban qué personas debían ser considerados como tales.

Efectivamente, la dificultad de clasificar a los vagos había sido ya notada como uno de los principales problemas para la aplicación de la norma, y desde fecha

${ }^{52}$ Véase: Aranda, J., El Marqués de la Ensenada: estudios sobre su administración (Madrid, 1898); Coronas, C. E. - Armillas, J. A., La España de las reformas (Madrid, 1989), pp. 109 ss.; o Gómez URdÁN̄ez, J. L., El proyecto reformista del Marqués de Ensenada (Logroño, 2008).

${ }^{53}$ En este último problema se basa la obra de Callaban, W., The Problema of Confinement: An Aspect of Por Relief in Eighteenth Century Spain, en Hispania American Historical Review 51 (febrero, 1971) 1, pp. 1-24.

${ }^{54}$ Dou y Bassols, R. L., Instituciones del Derecho público general de España con noticia del particular de Cataluña (1742-1832) (ed. Barcelona, 1975), libro II, título 9o, cap. 10, sec. $2^{a}$, p. 200.

${ }^{55}$ La citada Real Ordenanza de Vagos, de 30 de abril de 1745, aparece en PÉrez y López, A. X., Teatro de la legislación universal de España en Indias, por orden cronológico de sus cuerpos $y$ decisiones no recopiladas (Madrid, 1797), p. 443; y sobre su influencia en las colonias para la reactivación del ejército en los meses inmediatamente posteriores a su publicación, nos informan Arrom, S., Vagos y mendigos en la legislación mexicana (1745-1845), en Memoria del IV Congreso de Historia del Derecho Mexicano (México, 1987), I; Oyarzábal, G. A., La Armada española y el gobierno de Río de la Plata: aspectos formales e informales de una compleja relación (1760-1800), en $49^{\circ}$ Congreso Internacional de Americanistas (Quito, 1997); Alonso, G. F., El delito de vagancia durante el último cuarto del siglo XVIII, en Historias de la Ciudad. Una revista de Buenos Aires 11 (septiembre 2001); y Alonso, G. F. - BARral, M. E. - Fradkin, R.O. - PERRI, G., Los vagos de la campana bonaerense: la construcción histórica de una figura delictiva (1730-1830), en Prohistoria (2001). 
temprana algunos autores ilustrados habían emprendido la labor de determinar las distintas clases de pobres que existían. Por ejemplo, en 1741 José del Campillo y Cossío diferenciaba tres clases: los "verdaderos pobres" a los que había que asistir en los Hospicios, y los "pobres por su conveniencia" y "pobres en la apariencia”, a los que había que encerrar de forma coactiva, imponiéndoles medidas sancionadoras y obligándoles a trabajar ${ }^{56}$. La Real Ordenanza de 1745 fue la primera que, sin embargo, se hizo eco de tales clasificaciones en forma de ley, detallando las personas a las que debía considerarse "vagos" frente a los "verdaderos pobres":

"El que sin oficio ni beneficio, hacienda ó renta vive, sin saberse de que venga la subsistencia por medios lícitos u honestos: el que teniendo algún patrimonio ó emolumento, ó siendo hijo de familia, no se le conoce otro empleo que el de casas de juego, compañias mal opinadas, freqüencia de parajes sospechosos, y ninguna demostración de emprender destino en su esfera: el que vigoroso, sano y robusto en edad, y aun con lesión que no le impida exercer algun oficio, anda de puerta en puerta pidiendo limosna: el soldado inválido, que teniendo sueldo de tal, anda pidiendo limosna [...]: el hijo de familias que mal inclinado no sirve en su casa y en el pueblo de otra cosa, que de escandalizar con la poca reverencia u obediencia a sus padres, y con el ejercicio de las malas costumbres, sin propensión ó aplicación a la carrera que le ponen: el que anduviere distraido por amancebamiento, juego o embriaguez: el que sostenido de la reputación de su casa, del poder o representación de su persona, ó las de sus padres o parientes, no venera como se debe a la Justicia, y busca las ocasiones de hacer ver que no la teme, disponiendo rondas, músicas, bayles en los tiempos y modo que la costumbre permitida no autoriza, ni son regulares para la honesta recreación: el que trae armas prohibidas: [...] el que teniendo oficio no lo exerce lo mas del año, sin motivo justo para no exercerlo: el que con pretexto de jornalero, si trabaja un día, lo dexa de hacer muchos, y el tiempo que habia de ocuparse en las labores del campo, o recolección de frutos, lo gasta en la ociosidad [...]: el que sin visible motivo da mala vida a su mujer con escándalo en el pueblo: los muchachos que, siendo forasteros en los pueblos, andan en ellos prófugos sin destino: los muchachos naturales de los pueblos, que no tienen otro exercicio que el de pedir limosna, ya sea por haber quedado huérfanos, o ya porque el impio descuido de los padres los abandona a este modo de vida [...]: los que no tienen otro exercicio que el de gaiteros, bolicheros y santinbancos; porque estos entretenimientos son permitidos solamente en los que viven de otro oficio ó exercicio: los que andan de pueblo en pueblo con máquinas reales, linternas mágicas, perros y otros animales adiestrados, como las marmotinas, ó gatos que las imitan, con que aseguran su subsistencia, feriando sus habilidades, y las de los instrumentos que llevan, al dinero de los que quieren verlas, y al perjuicio de las medicinas que con este pretexto venden, haciendo creer que son remedios aprobados para todas las enfermedades: los que andan de unos pueblos a otros con mesas de turrón, melcochas, cañas, dulces y otras golosinas".

En suma, un amplísimo abanico de la sociedad, presuntamente relacionado con el vicio y el delito, del que formaban parte los jugadores, los ebrios, los soldados

${ }^{56}$ Campillo y Cossío, J. del, Dos escritos políticos. Lo que hay de más y de menos en España para que sea lo que debe ser y no lo que es. España despierta (ed. Oviedo, 1993), pp. 31-38, y 80-91. 
licenciados, los que llevaban armas prohibidas, los amancebados, los forasteros no avecindados, los niños y jóvenes mendicantes, e incluso los feriantes, músicos, saltimbanquis, titiriteros, charlatanes o nómadas dedicados al espectáculo público o a la venta ambulante. A su apresamiento iban dirigidas las sucesivas órdenes que a partir de entonces, y cada vez que lo consideraba conveniente, daba el monarca para el reemplazo de sus ejércitos dentro del marco legal establecido:

"Aunque la precisión de completar, y poner en el pie correspondiente los Regimientos de Infantería de el Exercito del Rey, que se halla en Campaña, para que no solo no sea mirado con desprecio de los Enemigos, ni por su debilidad arruinado con pérdida de tan bizarra, y apreciable Gente, sino es respetado, y temido, como lo ha sido hasta aqui, tanto por el honor de las Armas, y poder mantener el empeño de la Guerra, como por ser medio para asegurar una paz sólida, y ventajosa, pedía la mas prompta remessa de el numero de Gente capaz a ocurrir a tan precisa, como necessaria urgencia (...); considerando el paternal amor de S.M que esto no podría dexar de causar la mayor fatiga, y aflicción a los Pueblos [...], se ha servido (usando de su innata Real piedad, y propensión al alivio de sus Vassallos) mandar, que el reemplazo de la Infantería se execute de la Gente vagabunda, viciosa y mal entretenida, que se hallare en los Pueblos, y de los Reos que lo sean, no de delitos feos, y puedan en justicia aplicarse a las Armas" 57 .

La dificultad, no obstante, devenía de llevar este tipo de órdenes a la práctica: ¿quién detenía a los vagos? ¿dónde se custodiaban? ¿cómo se enviaban al ejército? ¿con qué recursos se sufragaba el procedimiento ¿ ¿cómo se coordinaban las justicias ordinarias de los pueblos con los órganos militares?

\section{LAS INSTRUCCIONES DE 1751 Y 1759 Y SU SUPLEMENTO DE 1765}

Las Instrucciones dictadas en 1751 y 1759 por la Secretaría de Guerra, que todavía dirigía el Marqués de Ensenada, trataron de determinar el procedimiento que debían aplicar los corregidores y justicias ordinarias para la detención, custodia, procesamiento y castigo de los ociosos en el ejército u otros destinos, tratando con ello de solventar los numerosos problemas que se habían suscitado para la aplicación de las leyes y mandamientos anteriores. Pero su contenido fue ignorado o incumplido hasta que, percibida del hecho la Secretaría, ordenó enviar ambas instrucciones al Consejo, en el año 1763, al objeto de que, tras hacer las consultas pertinentes, volviera a publicarlas con una "Explicación y suplemento" que las hiciera más fácilmente comprensibles $\mathrm{y}$, sobre todo, inmediatamente aplicables o ejecutivas.

Todo este conjunto normativo (las dos instrucciones, y su Explicación y Suplemento) se publicó en 1765, junto con el informe que previamente había realizado sobre su contenido la Sala de Alcaldes, y las dos respuestas fiscales de

${ }^{57}$ Carta circular del año 1746 a los corregidores y cabezas de partidos, encargándoles la aprehensión de ociosos y vagamundos de que se debía hacer el remplazo del ejército, en CoRONAS GONZÁlez, S., El libro, cit. (n. 50), I, libro III, n. 52, pp. 594-595. Véase otro ejemplo en el tomo I, libro II, n. 24, p. 26. 
Pedro Rodríguez de Campomanes y Lope Sierra ${ }^{58}$. Aunque en la exposición de motivos que precedió a todo ello, el rey achacaba únicamente el incumplimiento de las instrucciones de 1751 y 1759 al "poco zelo de las Justicias" y "la interposición de Personas poderosas, que protegen el vicio con el nombre de la piedad”, tanto la Sala de Alcaldes como los Fiscales de reino se mostraron mucho más expeditivos a la hora de depurar los motivos de su inaplicación. Para ellos, no sólo había sido la desidia de los jueces ordinarios lo que había provocado la ineficacia de las leyes, sino la indeterminación de las mismas y los escasos medios con los que habían contado, además de la alta falibilidad de las propias normas:

" $Y$ como el Fiscal está persuadido de que tales medios no se han facilitado completamente a las Justicias, no debe atribuir a los Jueces Ordinarios, ni a su pretendida desidia la multiplicación de los vagos, ni su impunidad. Por consiguiente, interin no se contenga del todo la mendiguez a los holgazanes sanos, y robustos, siempre habrá vagos, porque la mendiguez les subministra el alimento sin trabajar, oculta sus vicios con gran seguridad, los substrahe a la Justicia, y los presenta delante de ella, y del Pueblo con el semblante de personas miserables, y dignas de compasión; quando esencialmente son unos hombres estragados en lo moral, y que hurtan a los Pobres verdaderos el alimento, negándose al trabajo, que debe prestar todo hombre sano para ganar su pan"59.

Coincidían los fiscales y la Sala de Alcaldes en que el motivo principal de la inaplicación de la ley era la ambigüedad de los términos de vago y malentretenido, que hacía muy difícil a los corregidores o alcaldes tomar decisiones con respecto a su castigo. Según el informe de la Sala de Alcaldes, en este sentido ya se había realizado una importante regulación donde se especificaban todas las especies de vagos "en la Ordenanza de 30 de Abril de 1745, en su artículo 5 (que no fue publicada, al parecer, por superiores motivos ${ }^{60}$. Abundando en tales motivos, el fiscal López Sierra señaló, precisamente, la torpeza de haber dejado en las únicas manos de la justicia ordinarias la determinación de estas causas: "Créyose, que dando extensión a las facultades de las Justicias Ordinarias para obrar por si, y sin dependencia de los Tribunales Superiores, podría más bien conseguirse el fin de libertar los Pueblos de vagos, y mal-entretenidos; y sin lograr el fin que se deseaba, fue causa esta providencia de muchos inconvenientes, pues se vieron destinados al servicio de la Guerra, $y$ de los Arsenales muchos, que ni eran vagamundos, ni mal-entretenidos, y tolerados en los Pueblos los que padecian estos defectos, gobernándose sus Justicias por la dirección de un mal Escribano, o dejándose vencer sus pasiones, por la confianza de que sus procedimientos no habian de ser vistos en los Tribunales Superiores, y que

${ }^{58}$ Todo ello en Coronas González, S., El libro, cit. (n. 50), tomo III, libro VI, n. 70, pp. 1540-1568, aunque de forma separada las dos respuesta fiscales de Campomanes y López Sierra también han sido publicadas por Coronas González, S., Ilustración, cit. (n. 50), pp. 314-338, y comentadas por él mismo en pp. 138-142.

${ }^{59}$ Son palabras de Campomanes en Coronas González, S., El libro, cit. (n. 50), tomo III, libro VI, n. 70, p. 1554, que en el mismo sentido continúan en p. 1557: "Todas estas reflexiones demuestran, a lo que el fiscal entiende con evidencia, el poco fundamento con que se hace recaer sobre las Justicias Ordinarias, lo que es imperfección de las Ordenanzas, o omisión de los mismos Fueros privilegiados, que se crean continua, y arbitrariamente para suplir la pretensa negligencia de dichas Justicias, a las quales atribuyen la suya, y en que se padece una preocupación general".

${ }^{60}$ Coronas González, S., El libro, cit. (n. 50), tomo III, libro VI, n. 70, p. 1551. 
los Intendentes, a quienes se confió la observancia de la Instrucción, están ocupados en otros Negocios de mayor gravedad"61.

Ninguno de los medios anteriormente establecidos (como hacer padrones de mendigos o ponerles una tablilla o medalla con su nombre), habían funcionado a juicio de los informantes para determinar la calidad de vago, y junto a la indeterminación de los mismos se producían otros problemas, como su carácter nómada, que les hacía cambiar continuamente de pueblo, la falta de experiencia del nuevo proyecto utilitarista, y sobre todo la falta de medios que encontraban los jueces ordinarios para proceder al envío de vagos al ejército.

Ante las dificultades que las justicias de los pueblos encontraban para castigar a los vagos al servicio en armas, marina, arsenales u obras públicas, pena que sin duda "tuvo principio en edad más ilustrada y patriótica", éstos seguían decantándose aún por las antiguas penas de prisión, azotes o destierro, que habían resultado absolutamente ineficaces en el pasado, en opinión de Campomanes: La pena de prisión porque "no hai con qué mantenerlos en las Cárceles" y "se les suelta por no dexarles morir de hambre"; la de destierro porque en la naturaleza de estas gentes está el nomadismo, y con ella no se conseguía sino cambiar a los vagamundos de un pueblo a otro, y viceversa, sin que ninguno de los pueblos de España quedara libre de ellos; y la pena de azotes, además de ineficaz para disuadirles de su forma de vida, "tampoco se usa, por la compasión que los vagos infunden con el trage, y apariencias de mendigos" 62 .

La respuesta al problema era, en consecuencia, procurar el efectivo cumplimiento de la pena de servicio en el ejército prevista desde 1733, en la forma establecida por las Instrucciones de 1751 y 1759 , como reconocía el propio monarca en la exposición de motivos, imbuido sin duda del nuevo espíritu iluminista que ya había desarrollado las principales líneas de la economía política ${ }^{63}$. Pero para ello era necesario depurar previamente la calidad de vago o mal entretenido al que había que someter a la misma, y establecer con precisión el procedimiento, los órganos competentes en el mismo (sobre todo habida cuenta de la participación de la jurisdicción ordinaria y órganos militares), y los fondos con los que se costearía todo el proceso.

A ello se dedicó la "Explicación, y suplemento" de las Instrucciones de 1751 y 1759, que comenzaba, de hecho, determinado la calidad de vagos y mal entretenidos, que " no ha de entenderse unidamente; si no es que baste qualquiera de los dos requisitos para la aplicación a la Tropa, Marina, y Obras públicas"64. Por vago se

${ }^{61}$ Coronas González, S., El libro, cit. (n. 50), tomo III, libro VI, n. 70, p. 1566.

${ }^{62}$ Coronas González, S., El libro, cit. (n. 50), tomo III, libro VI, n. 70, p. 1555.

${ }^{63} \mathrm{Se}$ trataba, en palabras del propio rey, de solucionar el problema de la vagancia, que imponía "una intolerable carga al resto de la sociedad", y al mismo tiempo evitar "las perniciosas consecuencias de no completarse el Egercito para la defensa de los Reynos, la de haver quedado abandonada la Industria, la Agricultura, y el Comercio, sin las quales es imposible que se establezca la general felicidad, que las piadosas intenciones de S. M. desean ver plantificada para el alivio, y consuelo de sus amados vasallos". En Coronas GonZÁlez, S., El libro, cit. (n. 50), tomo III, libro VI, n. 70, p. 1540.

${ }^{64}$ Coronas González, S., El libro, cit. (n. 50), tomo III, libro VI, n. 70, pp. $1545-$ 1547. 
entendía, en términos generales (se redactaron para ello catorce largos artículos), aquellos que la anterior ordenanza de 1745 había señalado por mendicantes, o gentes que no tienen hacienda ni oficio, de cualquier edad, y estuvieran o no avecindados en los pueblos, siempre que fueran sanos y robustos. Se incluyó junto con ellos a quienes se dedicaran al oficio de buhoneros (además de los feriantes, embaucadores, saltimbanquis o titiriteros ya determinados), y a los falsos romeros o peregrinos, teniendo especial cuidado con los peregrinos extranjeros, a quienes se les exigiría a partir de entonces una autorización de sus prelados o un pasaporte de sus gobiernos, así como una licencia para peregrinar expedida por el jefe militar o político de la primera plaza o pueblo señalado por el que entraran en España.

Entre los vagos se debían incluir también los hidalgos sin renta ni trabajo ("no se opone al efectivo cumplimiento de la Leva la calidad de la hidalguía"), y "los estudiantes matriculados en las Universidades Literarias, que sólo toman este Título para mantenerse en una vida licenciosa", para lo cual se exigía a los rectores, maestre-escuelas o cancelarios que cada año remitiesen una lista de los alumnos reales y los sólo matriculados a los intendentes de sus respectivas provincias. Por el contrario, la explicación de las Instrucciones eximía expresamente de la calidad de vagos a ciertas clases dudosas, como los que estuvieren empleados en Estudios mayores o menores, los que tuvieran renta aunque no trabajasen, los artistas aún siendo sólo aprendices, los comerciantes, los criados y sirvientes, así como los peones, pastores, carreteros, tragineros y arrieros, siempre que trabajasen con cierta continuidad.

Frente a la ordenanza de 1745, la "Explicación" a las Instrucciones distinguía una segunda categoría junto a la de "vago" en sentido estricto: el "mal entretenido". Por tal se reputaban los ebrios, díscolos, jugadores, pródigos, turbadores de la paz pública, "los que dan molestia a sus mujeres continua, e injustamente, castigándolas con exceso", y "los que por vicio depravado hacen daño a las arboledas de los pueblos, las obras públicas, y las fuentes, y puentes".

A todos ellos se les prohibió el derecho de asilo eclesiástico, así como "el indiscreto refugio de la piedad, ni la protección de los Poderosos". Y en cuanto al procedimiento para su aprehensión y castigo, se determinó una doble instancia: Los corregidores u alcaldes ordinarios de los pueblos quedaron obligados, en primer lugar, a averiguar de oficio, y sin que lo llegaran a saber los pesquisados, quiénes eran los vagos y mal entretenidos que había en sus respectivas jurisdicciones, conminándoles a que lo hicieran con el mayor celo e imparcialidad (bajo la pena de suspensión de oficio, inhabilitación y otras). Sólo tenían que procurar la detención de los vagos o mal entretenidos (no simples mendigos o verdaderos pobres) de edades comprendidas entre los 12 y 50 años; y para prueba de su calidad bastaba el testimonio de tres personas "de notoria integridad y verdad".

Los detenidos debían ser custodiados en las cárceles públicas de cada lugar, manteniéndose en ellas con fondos públicos, y realizada una lista de los mismos por parte de los corregidores y justicias, se enviaban sólo al Intendente de cada cabeza de partido, con sus respectivos certificados, "los hombres que sean robustos, $y$ hábiles para las Armas, o trabajo personal; y de los que, por achacosos, se excluyan deberá 
embiarse al Corregidor Certificación de Médico, o Cirujano, que lo afirme, precediendo el reconocimiento del excluido en presencia del Cura Párroco, y Alcalde".

El detenido que se sintiese agraviado, podía recurrir ante el Intendente una vez llegado a la Caja militar de cada cabeza de partido, donde se volvía a custodiar a la espera de destino. El Intendente de la provincia era, en consecuencia, la segunda instancia que intervenía en el proceso, tanto para resolver los casos de injusticia notoria, como para juzgar y castigar la falta de celo o fraude de las justicias ordinarias, e incluso para suplir su competencia, practicando directamente las diligencias de pesquisa, detención y traslado a las Cajas militares en caso de negligencia u omisión de los corregidores o alcaldes de su jurisdicción. Sólo en casos excepcionalísimos, el Intendente podía remitir un dictamen a la Secretaría del Despacho Universal de la Guerra para que fuese el propio Secretario quien resolviese el recurso de algún detenido.

En consecuencia, desde la entrega de vagos en las distintas Cajas de provincia, la jurisdicción militar era la que pasaba a hacerse cargo de los mismos, y para ello se formaba una cuenta o relación de los socorros suministrados a los detenidos hasta su puesta en destino que se pasaba a la Secretaría de Guerra. La idea es que los detenidos pasaran el menor tiempo posible en las Cajas, y pronto se pusieran al servicio del rey en los destinos o regimientos más cercanos, para abaratar al máximo los costes.

En este sentido, los destinos contemplados para los vagos y mal entretenidos eran varios. Para los mayores de 18 años y menores de 50, que fuesen sanos, robustos y diesen la talla de cinco pies cumplidos, se preveía el servicio en cualquier regimiento del ejército (generalmente en cuarteles o castillos cercanos, pero también podía ser en presidios coloniales) por un periodo de cinco años. Para los mozos, o aquellos que no tuvieran la estatura correspondiente para las armas, la Instrucción de 1751 previó cambiar el servicio en el ejército por un servicio en los arsenales. Y para los que "siendo ociosos, no son apropósito para el Real Servicio, ni para trabajar en los Arsenales, por falta de robustez, u otro defecto grande, que puedan tener, no siendo justo, que por esto queden en libertad en perjuicio del Público; en este caso las Justicias los asegurarán, y darán destino en obras públicas".

Es decir, como después se encargaría de especificar la "Explicación y Suplemento", sólo los hombres robustos y sanos se enviaban a las Cajas para servir en el ejército o la marina, debiendo las justicias ordinarias de los pueblos buscar los destinos en obras públicas de quienes, siendo verdaderos vagos o mal entretenidos (y no mendigos o enfermos susceptibles de asistencia) no dieran la talla requerida.

En cuanto a los mozos de 12 a 18 años, la "Explicación y Suplemento" de 1765 también realizó una extensa regulación para especificar la naturaleza de sus destinos, con la finalidad de procurar su enmienda o corrección ${ }^{65}$. La primera vez que fueran detenidos se destinarían a la Marina, para que sirvieran en calidad de pajes de navío, grumetes o calafates, o en los arsenales o fábricas para la habilitación de navíos, hasta que cumplieran 20 años. Después quedaban libres

\footnotetext{
${ }^{65}$ Coronas González, S., El libro, cit. (n. 50), tomo III, libro VI, n. 70, pp. 1548-
} 1549. 
para que pudieran seguir dedicándose al mismo trabajo que habían aprendido, o a cualquier otro. Pero si no lo hacían en el plazo de un mes, podían volver a ser detenidos para pasar otros cinco años en el mismo destino, y así sucesivamente hasta su corrección.

También podían aplicarse como jornaleros en sus respectivos pueblos, para lo cual "deberán los Intendentes, Corregidores, y Alcaldes Mayores formar una Ordenanza clara, y expresiva para las Capitales, Villas, y Lugares de su Provincia, Corregimiento, y Partido, en que se arreglen los jornales, horas de trabajo, y cantidad de comida, y bebida, con distinción de labores, y estaciones del año”. Y, excepcionalmente, si algún maestro oficial, labrador honrado o persona calificada del pueblo, quisiera sacar de la Caja a algún muchacho de hasta 18 años para enseñarse un oficio o labor, podía hacerlo siempre que se responsabilizara de su crianza y educación, y se obligara a denunciar su fuga en caso de que ésta se produjera.

Finalmente, sólo para los mayores de 50 años y verdaderos enfermos o mutilados, se podían otorgar licencias de verdaderos mendigos: "Deberán las Justicias Reales dar licencia para que pidan (mientras no se disponen Hospicios competentes) a los Ancianos, o Estropeados, después de un prolijo examen de si es afectada, o fingida la necesidad que pretextan".

Determinadas todas estas disposiciones generales, la "Explicación y Suplemento" dedicó también algunos artículos a la particular policía de vagos y mal entretenidos en Madrid, "donde es mas excesivo que en otras Poblaciones el numero de los Vagos, y mal entretenidos" ${ }^{66}$. En atención a esta circunstancia, la ley predicaba una especial atención a la policía de vagos en la Corte, atribuyendo competencia para ello, junto a los Alcaldes de Casa y Corte o justicias ordinarias, al Corregidor y sus tenientes, y el Comandante militar, que quedaba obligado a prestar auxilio con su tropa para la detención de vagos y custodia en la Caja de corte, nunca en las cárceles. Era esta, sin embargo, una regulación notoriamente insuficiente para el especial azote de indigentes y vagos que estaba sufriendo Madrid y, muy poco tiempo después, a consecuencia del Motín de Esquilache que tuvo lugar al año siguiente de 1766, fue superada por una nueva administración policial, como veremos bajo el epígrafe siguiente.

\section{LA DIVISIÓN DE LAS CIUDADES CAPITALES EN CUARTELES Y BARRIOS, Y OTRAS MEDIDAS ADMINISTRATIVAS}

Aunque desde su llegada al trono, tras los acontecimientos de la Guerra de Sucesión, los nuevos reyes de la dinastía Borbón habían reforzado las medidas de policía destinadas al mantenimiento de la seguridad u orden público, un nuevo detonante que vigorizó en todos los sentidos esta legislación fue el motín popular que se desató en Madrid en 1766 contra el Marqués de Esquilache.

El motivo último de la revuelta fue un edicto municipal por el que se trataba de desterrar en la Villa de Madrid el uso de la capa larga y el chambergo (sombrero de ala ancha), para impedir que, ocultos ellos y sus armas tras tan amplios ropajes,

${ }^{66}$ Coronas González, S., El libro, cit. (n. 50), tomo III, libro VI, n. 70, p. 1549-1550. 
los delincuentes cometieran todo tipo de atropellos ${ }^{67}$. Ésta no era sino una más de las medidas de orden público que el ministro italiano venía acometiendo desde hacía tiempo, pero despertó la ira del pueblo por el descontento general que se tenía, fundamentalmente, debido a la carestía de bienes y el aumento de los precios. La revuelta ha sido concebida por ello como un clásico motín de subsistencias, aunque en su fondo latieran también otros conflictos sociales, y especialmente el acoso que estaban recibiendo los más pobres ${ }^{68}$.

La revuelta tomó forma el 24 de marzo, Domingo de Ramos, cuando una multitud incontrolada asaltó un cuartelillo de la plazuela de San Antón y se apoderó de sables y fusiles, uniéndolos a las armas que ya portaban, y se dirigió a las casas de los ministros italianos Esquilache, Grimaldi y Sabatini. El Lunes Santo la muchedumbre marchó hacia el Palacio Real, donde se había acogido Esquilache bajo la protección del rey, y un sacerdote que actuó como mediador ("el religioso de San Pedro de Alcántara”) hizo llegar a Carlos III una lista de exigencias, entre las que constaban el destierro de Esquilache, la sustitución inmediata de todos los ministros extranjeros, la desaparición de la Guardia Valona, la bajada de los precios de los comestibles, la desaparición de las Juntas de Abastos, la retirada de las tropas a sus cuarteles, y, por último, la conservación de la capa larga y el chambergo.

El monarca aceptó las peticiones, desatendiendo a quienes le aconsejaban sofocar la revuelta con las armas, y partió hacia Aranjuez con toda la familia real. Pero su marcha se consideró un desafío por el pueblo, que al día siguiente continuó con las revueltas, asaltando almacenes de comestibles, cárceles y cuarteles. El presidente del Consejo de Castilla, Diego de Rojas, fue tomado entonces como prisionero en su propia casa, y obligado a redactar una carta al rey en la que se le exponía la situación, y se le conminaba a ratificar su promesa de respetar las peticiones populares. El rey así lo hizo, aunque contestó que no regresaría a Madrid hasta que la ciudad estuviera completamente asegurada.

Pacificado el tumulto, en junio de 1766 el monarca tomaba su última decisión al respecto, tras recibir las cinco representaciones que le presentaron con su opinión la Nobleza, la Villa de Madrid, los Gremios Mayores, los Gremios Menores y el Cabildo Eclesiástico de Madrid, y considerar también la respuesta de los Señores Fiscales y el parecer del Consejo ${ }^{69}$. En términos generales, las representaciones citadas dejaban constancia de la fidelidad de los cuerpos que las firmaban al rey, y ponían de manifiesto su condena a "el tumultuoso detestable exceso de la plebe”. En su opinión el motín (en el que participaron mucho miles de

${ }^{67}$ Esta política había comenzado en enero del mismo año, cuando Carlos III prohibió este tipo de atuendo a los empleados en el servicio y oficinas reales, en NoR. 6, 13, 14. El bando prohibitivo de la capa larga, el sombrero chambergo o redondo, la mantera calada o embozo en la Corte, puede consultarse en la Nov. Rec. 3,19,13.

${ }^{68}$ Véanse: Macías Delgado, J., El motín de Esquilache a la luz de los documentos (Madrid, 1988); y Ferrer Benimelli, J. A., Don Ramón Pignatelli y el motín de Esquilache: una nueva versión del motín de Zaragoza, en Actas del I Symposium del Seminario de Instrucción Aragonesa (Zaragoza, 1987).

${ }^{69}$ Coronas González, S., El libro, cit. (n. 50), tomo II, libro V, n. 121, pp. 1314-1321. 
personas en Madrid y otros lugares) había sido promovido simplemente por "una colecticia porción de mal-entretenidos, y desechos forasteros", que no podían asumir la representación del pueblo, ni mucho menos imponer leyes a la soberanía del rey, y por eso "ruegan rendidamente a V.M. se digne de anular dichas gracias: pues en quanto pende de los Suplicantes, las tiene por ineficaces, $y$ de ningún momento: $y$ que se compadezca de este Pueblo, para consolarlo con su amable presencia”. Así lo hizo Carlos III, resolviendo que efectivamente aquellas pretensiones del pacto se tuvieran por nulas e ineficaces.

A continuación, el monarca adoptó una férrea política para el mantenimiento del orden público en la Corte, con medidas como la que declaraba la nulidad de los indultos o perdones que concedieran los magistrados o ayuntamientos por causa de alboroto o revuelta ${ }^{70}$; la que derogaba todo fuero privilegiado en dichas causas, otorgando su conocimiento a las justicias ordinarias ${ }^{71}$; la que prohibía la publicación y difusión de pasquines u otros papeles sediciosos o injuriosos a personas públicas o particulares ${ }^{72}$; la que reguló el comportamiento de los concurrentes a los coliseos o teatros públicos al objeto de evitar cualquier desorden ${ }^{73}$; o, por lo que a este tema más interesa, la que prohibía que los ociosos o mal entretenidos frecuentaran cafés, botillerías o mesas de truco, o que pasearan continuamente por las plazas o esquinas, para evitar que pudieran estar fraguando una nueva revuelta ${ }^{74}$.

Como hemos visto, a este grupo social de ociosos y vagos, acaudillado o dirigido contra el gobierno por la Compañía de Jesús (que como es conocido fue expulsada del país tras el motín ${ }^{75}$ ), fue al que en gran medida se le responsabilizó de la revuelta, que se componía a juicio del resto de cuerpos sociales "de lo vago, mendigo y advenedizo más despreciable" ${ }^{76}$. Ellos eran los descontentos, perseguidos, depravados y malhechores a quienes había que reducir por todos los medios, puesto que comenzaban a ser una amenaza cada vez más seria contra la monarquía. Y para ello no sólo se les prohibió frecuentar tabernas o lugares de vicio, o pasear por la ciudad sin motivo, sino que se adoptaron medidas substanciales dirigidas principalmente a controlarles a través de una reforma estructural de la administración municipal madrileña.

De tal manera, por medio de la Real Cédula de 6 de octubre de 1768 se pro-

\footnotetext{
${ }^{70}$ Nov. Rec. $12,11,3$.

${ }^{71}$ Coronas González, S., El libro, cit. (n. 50), tomo II, libro V, n. 136, pp. 1333-1334, y Nov. Rec. 12,11,4.

${ }^{72}$ Coronas González, S., El libro, cit. (n. 50), tomo II, libro V, ns. 108 y 109, pp. 13001301, y Nov. Rec. 12,25,8, que recopila el Auto Acordado de 14 abril 1766, y la posterior Resolución que, ante el descontento popular que precedió a los acontecimientos de la Guerra de la Independencia, dictó Carlos IV en 18 diciembre de 1804 sobre el mismo asunto.

${ }^{73}$ Los bandos en este sentido dados por Carlos III en 1766, se recogen en Nov. Rec. $7,33,11$

${ }^{74}$ Bando de 15 de mayo de 1766, en Nov. Rec. 3,19,12.

${ }^{75}$ Egido López, T., La expulsión de los jesuitas de España, en Historia de la Iglesia en España, (Madrid, 1979), IV, pp. 746-792.

${ }^{76}$ Coronas González, S., El libro, cit. (n. 50), tomo II, libro V, n. 121, p. 1314.
} 
cedió a la división de Madrid en ocho cuarteles ${ }^{77}$. En cada uno de ellos habría un “alcalde de quartel' con amplia jurisdicción criminal, y en dependencia del mismo ocho "alcaldes de barrio" para ayudarle en sus funciones, que se especificaron poco después en la Instrucción de 21 de octubre del mismo año ${ }^{78}$. Entre ellas, era una función principal de los mismos matricular a todos los vecinos del barrio, conociendo cómo y de qué vivían, e incluso teniendo puntual noticia de todos los que acudían a las posadas, tabernas, casas de juego o botillerías, que debían visitar frecuentemente. A los pobres verdaderos y niños abandonados, debían recogerlos para llevarlos a los hospicios o que se les procurara algún lugar donde aprender un oficio o servir; y a los vagos o mal entretenidos, de quienes se les encargó su especial policía, tenían que ponerlos a disposición del alcalde de cuartel para que éste los derivase al de Sala y, tras realizarse el juicio sumario correspondiente, se enviaran lo antes posible a la Caja de la corte para que sirvieran al ejército o destino alternativo: "Como por la matricula, que deben formar los dichos Alcaldes de barrio de todos los vecinos del suyo, y de los demás que entren y salgan en ellos, y por las visitas freqüentes que en horas excusadas han de hacer en todas las posadas públicas y secretas, adquirirán forzosamente un perfecto conocimiento de todos los habitantes de su respectivo barrio, sus empleos y oficios, es preciso que descubran los que se hallen sin destino, los mendigos, los vagos, y los niños abandonados por sus padres ó huérfanos: por tanto se les encarga muy seria y estrechamente, que atiendan á todos los que se hallaren de estas clases, y den cuenta al Alcalde de su respectivo quartel, para que se destinen al hospicio los mendigos que no puedan aplicarse á las armas ó marina”.

La bondad de esta la medida en Madrid, donde al menos se sometió a un rigurosísimo control a la población ${ }^{79}$, determinó que un año después, por Real Cédula de 13 de agosto de 1769 , se extendiera al resto de las principales capitales de la monarquía ${ }^{80}$, incluidas las de las colonias americanas ${ }^{81}$, sin que con ello se consiguiera, no obstante, acabar definitivamente con el problema de los vagos.

Desde el fortalecimiento de los órganos de la administración, el dificultad no estaba ya tanto en la determinación y aprehensión de los holgazanes, sino en su destino, porque ¿qué se hacían con los miles de ociosos, mendigos voluntarios, pícaros o pequeños delincuentes que campaban por los distintos lugares del país? Aunque la ley establecía su servicio en el ejército, la marina o arsenales, u obras públicas, desde el principio se hizo necesariamente una interpretación extensiva

${ }^{77}$ Nov. Rec. 3,21,9.

${ }^{78}$ Nov. Rec. 3,21,10.

${ }^{79}$ Véanse: Cuesta Pascual, P., Los alcaldes de barrio en el Madrid de Carlos III y Carlos IV, en Anales del Instituto de Estudios Madrileño 19 (1982); y MarTínez RuIz, E., La seguridad pública en el Madrid de la Ilustración (Madrid, 1988), pp. 181 ss.

${ }^{80}$ Guillamón, J., Las reformas de la administración durante el reinado de Carlos III (Un estudio sobre dos reformas administrativas de Carlos III) (Madrid, 1980), pp. 263-359; o, por ejemplo, Tuero BerTRAnd, F., Alcaldes de cuartel, alcaldes de barrio y autos de buen gobierno en el Oviedo del siglo XVIII, en el Boletín del Instituto de Estudios Asturianos 80 (Oviedo, 1973).

${ }^{81}$ Véase: Arrazola, L., Enciclopedia española de Derecho y Administración, o Nuevo Teatro Universal de la Legislación de España e Indias (Madrid, 1849), II, pp. 460-462 y 464-465, así como, por ejemplo, Dyм, J., La policía de Nueva Guatemala: la disputa de los alcaldes de barrio, en el VII Congreso de Historia Centroamericana (Tegucigalpa, Honduras, julio 2004). 
de la norma, tratando de procurarles de hecho ocupaciones suficientes. En este sentido, resulta especialmente ilustrativa la Real Cédula de 15 de mayo de 1770 , por la cual se aprobaba el Auto de Buen Gobierno dado por la Audiencia de Canarias para poder poner a los holgazanes, o delincuentes menores, al servicio de vecinos honrados en barcos particulares al objeto de que aprendiesen y desarrollasen el oficio de la pesca ${ }^{82}$.

El auto de la Audiencia canaria se basaba en que "por la Ley quinta, titulo once, libro octavo de la Recopilación está autorizado qualquier Vecino de estos Reynos, para que pueda precisar a los Vagamundos a que le sirvan por tiempo determinado sin salario alguno, cuya compulsión, que parece repugnante en el estado de libertad en que estos se hallan, está calificada de justa en odio de la perversidad del vicio de la ociosidad, cuyos daños y perjuicios pondera justamente la misma ley". Las condiciones establecidas fueron, entre otras, que no se recibieran más de dos forzados por barco, que hubiese hombres suficientes para controlarles, que se les diera comida y alimento y se les enseñara el oficio, o que el patrón diera inmediata cuenta de ellos a la justicia cuando el barco tomara tierra.

Tan novedoso auto no dejó de ser una excepción en el conjunto de la monarquía pues, aun cuando ciertamente la legislación permitía que los vecinos honrados se ocuparan de los vagabundos para enseñarles un oficio, la medida no se había dotado de los recursos ni procedimientos necesarios para hacerla ejecutiva, ni contaba tampoco con el apoyo de la población. Los vecinos honrados no querían ni podían responsabilizarse de la suerte de los vagos, y sólo trataron de servirse de ellos con una torcida intención: la de que éstos les sustituyeran en el servicio del ejército una vez que los mozos ya habían sido sorteados para los reemplazos, lo cual fue expresamente prohibido por Carlos III en $1773^{83}$.

\section{LAS ÚLTIMAS MEDIDAS CONTRA VAGOS A FINALES DEL SIGLO XVIII}

La policía de vagos sufrió un nuevo impulsó con la Ordenanza de levas dada por Carlos III el 7 de mayo de 1775. En ella, se seguían puntualmente las recomendaciones de Campomanes, que aconsejaba hacer al menos una leva anual en las capitales, pueblos numerosos y otros lugares donde solieran encontrarse vagos, para recoger a los que fueran útiles y destinarlos al servicio de armas. La obligación anual ayudaría, sin duda, a ir restringiendo poco a poco el número de holgazanes, habida cuenta de que con las disposiciones anteriores no se habían conseguido los efectos deseados: "Sin embargo de que sobre esta materia de levas y recogimiento de vagos han sido varios los decretos, resoluciones y ordenanzas expedidas en diferentes tiempos, sin haber producido los saludables efectos que se deseaban, á causa

${ }^{82}$ Véase la Real Cédula de su Majestad de 15 de mayo de 1770 aprobando el Auto de la Real Audiencia de Canarias que proponía el servicio en los barcos de pesca para los vagos, en Coronas González, S., El libro, cit. (n. 50), tomo III, libro VII, n. 50, pp. 1717-1723.

${ }^{83}$ Véase la Real Cédula de S.M. y Señores del Consejo, de 28 de octubre de 1773, por la cual se declara que el aprehender, o denunciar los vagos, y mal entretenidos, no debe libertar al aprehensor, o denunciador de la suerte que le haya cabido o pueda tocarle, en CORONAS GonZÁlez, S., El libro, cit. (n. 50), tomo III, libro IX, n. 27, pp. 1935-1936. 
de no estar simplificado el método del procedimiento, no dado los medios prácticos que ahora dispenso á beneficio del útil destino de unas gentes, que en nada aprovechan al Estado en común ni en particular; mi voluntad es, que todas las referidas ordenanzas, resoluciones y decretos queden desde ahora sin fuerza ni vigor, y reducidas á esta Ley y ordenanza general, que se ha de observar inviolablemente; y á mayor abundamiento las revoco, derogo, y doy ningunas" 84 .

Para simplificar al máximo el procedimiento, como rezaba el espíritu de la reforma, la realización de estas levas anuales se encargó privativamente a los jueces ordinarios o de primera instancia en cada pueblo, inhibiendo a otras jurisdicciones, y especialmente las jurisdicciones privilegiadas. Los detenidos debían ser custodiados en las cárceles ordinarias, asegurándoseles con prisiones (esto es, cadenas, cepos o grillos) para evitar su fuga, si bien se encargaba a los jueces que procedieran en sus causas "con la preferencia, actividad y zelo que exige" para que su estancia y manutención fuera lo más breve posible.

Los considerados aptos para el ejército debían tener una edad de entre 17 y 36 años, y ciertas condiciones físicas fijadas en la ley, como una altura mínima de cinco pies. En general, la condición de vago se presumía del mismo elenco de personas que ya habían determinado las leyes anteriores (jugadores, ociosos, mendigos robustos, gente de vida nómada, titiriteros...), y que el propio Campomanes fijó por categorías en cinco completos informes que envió al conde de Floridablanca para "colocar a cada pobre en su destino" 85 . Para la prueba de su calidad dejó de exigirse el testimonio de al menos tres vecinos honrados, y bastaba "información sumaria con citación del Síndico general o Personero del Común”.

Otra condición prevista en la Ordenanza de 1775 era pertenecer al estado civil de soltero ${ }^{86}$. Pero para evitar los numerosos matrimonios de conveniencia que comenzaron a producirse entonces entre los vagos al objeto de evitar el servicio de armas, tan sólo un año después Carlos III derogaba dicho privilegio matrimonial, enviando a los ejércitos tanto a solteros como a casados ${ }^{87}$.

Todos ellos, una vez juzgados de forma sumaria, debían ser conducidos hasta la cabeza de partido, desde se conducían al Depósito más cercano ya bajo la responsabilidad del Capitán o Comandante General. Para simplificar esta labor, las numerosas Cajas previstas por la Instrucción de 1759 (había un total de 14 Cajas

\footnotetext{
${ }^{84}$ Nov. Rec. $12,31,7$, n. 41.

${ }^{85}$ Todos ellos trascritos y publicados por: VeLÁzquez, M., Desigualdad, indigencia y marginación social en la España ilustrada: las cinco clases de pobres de Pedro Rodríguez Campomanes (Murcia, 1991), pp. 149 ss.

${ }^{86}$ Nov. Rec. $12,31,7$, n. 9.

${ }^{87}$ Nov. Rec. 12,31,8: "Habiendo acreditado la experiencia, que muchos vagos y mal entretenidos toman el estado del matrimonio, con el objeto de continuar en sus desarregladas vidas, sin la contingencia de ser aprehendidos como tales, y aplicados al servicio de las armas, con arreglo al artículo 9 de la última ordenanza de levas; y conviniendo al bien de mi servicio y de la causa pública cortar los graves perjuicios que de su observancia se originan; he venido en derogar el citado artículo 9, y mandar, que no solo fuesen comprehendidos en la leva los que se hallen en iguales circunstancias, sino también qualquier reo que se halla detenido por alguno de aquellos delitos, que no siendo contrarios á la común estimación de las familias, ni de los mismos que los cometen, no se oponen al honroso servicio de las armas".
} 
Generales en Almagro, Zaragoza, Valencia, Murcia, Burgos, León, Jaén, Málaga, Cádiz, Sevilla, Écija, Algeciras, Granada y Badajoz), se redujeron por esta ley a 4 Depósitos: "Tengo por bien y he mandado, que á este efecto se formen quatro depósitos para recibir toda la gente de leva: uno en la Coruña, otro en Zamora, otro en Cádiz, y el quarto en Cartagena; suprimiendo y anulando las caxas establecidas por anteriores ordenanzas de levas ó vagos, por deberse remitir única y precisamente, según la mayor cercania, toda la gente de leva á los referidos quatro depósitos generales"88.

En 1779, el monarca fijaba definitivamente el tiempo del servicio de armas para que todos estos peculiares penados cumpliesen la misma condena en 8 años, "deseando evitar el disgusto, que una odiosa diferencia en el tiempo podría ocasionar entre los individuos de un Cuerpo" ${ }^{89}$. Ese mismo año, también se enviaron distintas Circulares a los pueblos para concretar el destino de los desertores, sobre el que se habían suscitado dudas ("a todo vago que deserte y sea aprehendido, se imponga la pena de servir por un año en las obras públicas de estos Reynos; y cumplido este término, que pase a servir en los Regimientos fixos de America por el tiempo de ocho años"); y para resolver algunas otras cuestiones confusas en la interpretación de la Ordenanza de levas, reiterando los puntos principales de la misma para asegurar su observancia ${ }^{90}$.

A partir de ese momento, los esfuerzos del gobierno se volcaron en conseguir que la ley se cumpliera en la práctica, dictándose sucesivas medidas que recordaban sus obligaciones a los oficiales responsables de su ejecución, tanto civiles como militares (corregidores y alcaldes ordinarios, ayudados en su caso por los alcaldes de cuartel y de barrio, capitanes generales, comandantes de tropas destinadas a la persecución de contrabandistas y salteadores, presidentes y regentes de las $\mathrm{Au}$ diencias, etc. ${ }^{91}$; y enviándose incluso oficiales especialmente comisionados para la aprehensión de vagos a las distintas Audiencias ${ }^{92}$.

De entre las numerosas leyes que se dictaron en relación a toda esta problemática de los vagos, resulta interesante reparar en el contenido de una de ella, señalada ya por Tomás y Valiente, en la que "la Monarquía ilustrada se muestra a medio camino entre la visión estamental de la sociedad, aún dominante, y el igualitarismo liberal, ya incipiente" 93 . Se trata de la ley dictada por Carlos III en 1781 para que los nobles vagos o malentretenidos no pudieran eximirse del castigo a su ociosidad, si bien "se destinen al servicio de armas en calidad de soldados distinguidos" ${ }^{94}$.

${ }^{88}$ Nov. Rec. 12,31,7, n. 24.

${ }^{89}$ Coronas González, S., El libro, cit. (n. 50), tomo IV, libro XI, n. 39, pp. 2317-2318, y Nov. Rec. 12,31,9.

${ }^{9}$ Coronas Gonzalez, S., El libro, cit. (n. 50), tomo IV, libro XI, n. 49, n. 60, n. 62 y n. 67, pp. 2328-2329, 2336, 2337-2338, y 2339-2340.

${ }^{91}$ En Nov. Rec. 12,31,14-18

${ }^{92}$ Según Sempere y Guarinos, J., Policía, cit. (n. 15), p. 129: "Sólo en el territorio de la de Granada destinó su comisionado en el año de 1793 mas de seis mil á las armas, y marina".

${ }^{93}$ Tomás y Valiente, F., El derecho penal de la monarquía absoluta (siglos XVI, XVII y XVIII) (Madrid, 1969), pp. 323-324.

${ }^{94}$ Coronas Gonzalez, S., El libro, cit. (n. 50), tomo IV, libro XII, nn. 27 y 28, pp. 2438-2439, y NoR. 12, 31, 11. 
Poco después, a vueltas con la determinación de la calidad de vago, Carlos III vino a responder a varias representaciones y recursos que se habían presentado al Consejo Real sobre el tema con una Real Cédula de 23 de marzo de 1783, en la que ordena que no "se consienta ni permita, que los buhoneros, y los que traen cámaras obscuras, y animales domesticados con habilidades, anden vagando por el reyno: con prevención que hago a los Capitanes generales y Justicias, que no les den pasaportes, y aunque los traigan, se les recojan, y destine como vagos [...] á las armas, marina, hospicios y obras públicas. Igualmente, [...] mando que sean comprehendidos por vagos los romeros ó peregrinos que se extravian del camino, y vagan en calidad de tales romeros; y que los escolares, solo yendo de las Universidades á sus casas via recta, puedan recibir pasaportes de los Rectores y Maestres de Escuela de las Universidades literarias; pues los que contravengan, deben ser también tratados como los demás vagos sin diferencia alguna. En quanto á los vagos extrangeros aptos para las armas, declaro, que pueden servir útilmente en los regimientos de su respectiva lengua, que están al servicio de la Corona [...]. Por lo respectivo á los que se llaman saludadores, y los loberos, mando ansimismo, que sean comprehendidos en la clase de vagos, y tratados como tales, observándose en la substanciación de sus causas generalmente lo dispuesto en la citada Real ordenanza de levas" $"$.

Tampoco se permitió que para el conjunto de los vagos, nobles o del común, tuvieran efecto los indultos generales que cada cierto tiempo publicaban los monarcas, bajo el también muy ilustrado razonamiento de que "la aplicación a las Armas, o Marina de los Vagos, ociosos, y mal entretenidos, no es pena, y si un destino precaucional para impedirles que caygan en delitos, y obligarles a que sean utiles a la Patria; y lo mismo sucede con los destinados a Hospicios, y Casas de Misericordia; y por consiguiente, no debiendo reputarse estas providencias de policía como penas, y si como determinaciones paternas para mejorar las costumbres de los Ciudadanos, no caen baxo el concepto de causas criminales" ${ }^{\text {. }}$.

\section{EL DESTINO DE LOS VAGOS “INEPTOS” Y VERDADEROS POBRES}

Hemos visto hasta aquí la policía de vagos y mal entretenidos, considerados éstos como una clase especial separada de otra serie de pobres verdaderos, y siempre que resultaran útiles, por edad, salud y condiciones físicas, para el servicio de las armas u otros destinos similares. Pero ¿qué ocurría con los otros vagos, a los que la legislación comenzó a llamar "ineptos”, cuando no podían ocupar dichos destinos? ¿y con los verdaderos pobres?

Los pensadores iluministas venían desarrollando, como ya se ha dicho, una crítica feroz contra las formas de asistencia tradicional, que estaban en manos privadas y no ofrecían los resultados deseables a la sociedad ${ }^{97}$. Siguiendo las ideas que ya apuntaran en el pasado hombres como Juan de Medina, Juan Luis Vives,

\footnotetext{
${ }^{95}$ NoR. 12, 31, 13.

${ }^{96}$ Coronas González, S., El libro, cit. (n. 50), tomo IV, libro XII, n. 9, pp. 2368 2369.

${ }^{97}$ Trinidad, P., Asistencia y previsión social en el siglo XVIII, en AA. VV., De la beneficencia al bienestar social: cuatro siglos de acción social (Madrid, 1986), pp. 89-90.
} 
Miguel de Giginta o Cristóbal Pérez de Herrera, a los que citaban constantemente $^{98}$, ellos proponían el cierre del ingente número de hospitales, casas de arrepentidas, casas de huérfanos o casas de misericordia, que habían proliferado durante el siglo XVII para recoger a la enorme masa de mendigos surgidos de la crisis, y la creación en su lugar de otro tipo de "hospicios generales", gestionados por la Administración pública, y con un plan uniforme de ejercicios y de gestión, en los que se separase a los vagos inhábiles o "ineptos" de los pobres verdaderos, y éstos a su vez según su condición (ancianos, niños, mujeres, enfermos, etc.), y se fomentase la educación popular y el aprendizaje de un oficio ${ }^{99}$.

Pero esta idea, aun cuando fuera la mejor de las soluciones, contaba con demasiadas dificultades en la práctica, siendo la primera y más importante de orden económico. Y así lo apuntó desde un primer momento el propio fiscal Campomanes, cuando, al informar en 1765 las Instrucciones de 1751 y 1759, así como su explicación y suplemento, afirmaba que: "este pensamiento de recluir todos los verdaderos mendigos es muy loable, bien que requiere tiempo para su ejecución, aplicando las Obras pías, fondos de Cofradias, de Hospitales mal administrados, y de otros efectos de esta naturaleza, a tan provechoso objeto, procediendo de acuerdo con la Justicia, y Diputaciones de Parroquia, los Curas, y Ordinarios Eclesiásticos" ${ }^{100}$.

Mientras tanto, y hasta que se alcanzasen los fondos suficientes para poner en marcha tan ambicioso proyecto, se continuó aplicando la legislación tradicional que proponía, por un lado, el control de la mendicidad a través de padrones y licencias; y, por otro lado, dejaba la labor de asistencia a una multiplicidad de establecimientos benéficos, la mayoría de carácter religioso, aunque a ellos comenzaron a sumarse algunos "hospitales" públicos. Los vagos "ineptos" podían acogerse a esta segunda opción de la asistencia si no querían ser apresados y destinados a los servicios alternativos al ejército que para ellos estaban previendo las leyes antes citadas $^{101}$.

${ }^{98}$ Todos ellos se citaban abundantemente por los ilustrados, y la obra del padre Medina, De la órden que en algunos pueblos de España se ha puesto en la limosna, para el remedio de los verdaderos pobres (Salamanca, 1545), que por primera vez en España advertía de los problemas de la asistencia tradicional, fue incluso mandada reimprimir en Valencia en 1757, y en Madrid en 1766, bajo el título de Caridad discreta, practicada con los mendigos, y utilidades que logra la república en su recogimiento.

${ }^{99}$ Sin ánimo de ser exhaustiva, véanse, entre otros, Jovellanos, G. M., Discurso acerca de la situación y división interior de los hospicios con respecto á su salubridad, en Obras, V, pp. 431 ss.; Campomanes, P. R. DE, Discurso sobre el fomento de la industria popular (Madrid, 1774, ed. Instituto Estudios Fiscales, Madrid, 1975); WARd, B., Obra Pía., cit. (n. 46); AnZANo, T. DE, Elementos preliminares para poder formar un sistema de gobierno de Hospicio general (Madrid, 1778); Murcia, P. J., Discurso politico sobre la importancia y necesidad de los hospicios, casas de expósitos y hospitales (Madrid, 1798); Meléndez Valdés, J., Discursos, cit. (n. 45), pp. 272 ss; o Sempere y Guarinos, J., Policía, cit. (n. 15), y Sobre la prudencia en el repartimiento de la limosna (Madrid, 1784).

${ }^{100}$ Coronas González, S., El libro, cit. (n. 50), tomo III, libro VI, n. 70, p. 1560

${ }^{101}$ En este sentido, repárese por ejemplo en el Aviso dado al público el 29 de junio de 1766, tras crearse el Real Hospicio de la Corte, para los que quisieran voluntariamente entrar en él para evitar otros destinos de trabajo previstos en la ley, en Coronas GonzÁLEZ, S., El libro, cit. (n. 50), tomo II, libro V, n. 122, p. 1321. 
Durante todo el siglo XVIII siguieron dictándose gran cantidad de leyes sobre licencias de pobres, limitándose la mendicidad a los territorios jurisdiccionales de cada obispado ${ }^{102}$; impidiendo a los mendigos autorizados pedir dentro de las iglesias, ni en sus puertas o claustros ${ }^{103}$; prohibiendo postular en la corte a los limosneros de ermitas, santuarios, comunidades de pobres, santos u otro cualquier título, porque "con esta maliciosa sagacidad se intenta vulnerar el recogimiento de Pobres, y Mal-Entendidos" ${ }^{104}$; e incluso vedando el uso tradicional de pedir limosna a los miembros de las propias órdenes mendicantes, a cualquier eclesiástico, nacional o extranjero, secular o regular, y a los peregrinos ${ }^{105}$.

Los órganos competentes para el otorgamiento de las licencias y el control de pobres eran, como sabemos, las justicias ordinarias en connivencia con los párrocos de la zona, aunque ya en fecha temprana comenzaron a comisionarse a algunos oficiales particulares para ocuparse de la beneficencia o reparto de ayudas, como por ejemplo el que se nombró en 1737 para Andalucía con el título de "Comisario Subdelagado" del rey: "Las frequentes noticias, que llegan a los Reales oidos de su Magestad, assi en recursos particulares, como en representaciones de los Corregidores, Ciudades, y Comunidades de las Provincias de la Andalucía, manifestando la summa infelicidad, a que las repetidas esterilidades de los años próximos passados, y la de el presente, han ocasionado en ellas, y que ya se ven andar por los campos diferentes quadrillas de hombres, y mujeres, mendigando el natural sustento, han obligado su piadoso Real magnánimo corazón a dar quantas providencias sean imaginables, para subvenir en todo lo posible a su amados Vassallos; y considerando su paternal cuidado, que para ocurrir mas de cerca a las necessidades de los Pueblos, y pobres Vecinos de ellos, es conveniente nombrar sugeto de conocidas circunstancias, inteligencia, buen zelo, y experimentada conducta, que con titulo de Comissario Subdelegado mio, tomo a su cargo acudir donde la necesidad más urge, y providenciar quanto convenga al reparo de las aflicciones, assi para no frustrarse el importante fin de la sementera, como para ocurrir al no menos grave assumpto de la subsistencia de los pobres Labradores [...]"106.

Como el problema era especialmente acuciante en la ciudad de la Corte y los Sitios Reales, también para ellos se dictaron una multiplicidad de leyes y órdenes que prohibían la mendicidad y ordenaban el recogimiento de los mendigos ${ }^{107}$.

${ }^{102}$ Circular de octubre de 1757 para que las licencias que el Consejo concediere para pedir limosna sea con limitación en el Obispado de sus territorios, al objeto de evitar "los excessos, y abusos, que cometen las personas, que andan vagantes por el Reyno con demandas de diferentes Santuarios...", en Coronas González, S., El libro, cit. (n. 50), tomo II, libro IV, n. 70, p. 989, y NoR. 1, 28, 7.

${ }^{103}$ Coronas González, S., El libro, cit. (n. 50), tomo IV, libro XI, n. 53, p. 2333.

${ }^{104}$ Bando de 16 de septiembre de 1766, en Coronas González, S., El libro, cit. (n. 50), tomo II, libro V, n. 135, pp. 1332-1333.

${ }^{105}$ Véanse la Carta circular de 1772, en Coronas González, S., El libro, cit. (n. 50), tomo III, libro VIII, n. 57, pp. 1874-1875, y Nov. Rec. 1, 28, n. 6; y la Real Cédula de 24 de noviembre de 1778, en Coronas GonZÁlez, S., El libro, cit. (n. 50), tomo IV, libro XI, n. 1, pp. 2209-2212, y Nov. Rec. 1,28,11.

${ }^{106}$ Coronas González, S., El libro, cit. (n. 50), tomo I, libro II, n. 116, pp. 368-369.

${ }^{107}$ Véanse las normas publicadas por CoROnas GonZÁlez, S., El libro, cit. (n. 50), tomo 
En esta villa de Madrid, como en las otras grandes capitales del reino, eran competentes junto a los corregidores y alcaldes ordinarios, desde 1768, los "alcaldes de quartel" y "alcades de barrio" a los que antes se ha hecho referencia, y a ellos se enviaron desde su creación las particulares órdenes para el recogimiento de mendigos y vagos ineptos. Repárese el destino al que, en las distintas órdenes dictadas en los años 1777 y 1778, se les ordenaba enviar a los mendigos que recogieran en Madrid, tras advertirles una vez más que este recogimiento "ha de ser continuo sin intermisión alguna": "Serán recogidos indistintamente todos los mendigos que se hallasen pidiendo limosna, y conducidos a los hospicios de Madridy San Fernando los Impedidos, y las Mugeres, y Niños de ambos sexos; pero las preñadas se llevarán a las Casas de Misericordia destinadas a este fin, y los válidos serán aplicados a los servicios de guerra, y marina [...]. La Sala aplicará por ahora a la marina a los muchachos de diez años arriba, sin perjuicio de poder poner a oficio aquellos que en el día considere proporcionados, respecto que los primeros pueden destinarse a las maestranzas en las Fábricas de Jarcia, y demás peltrechos, o a los Oficios de Carpintería de Ribera, según sus disposiciones, o servir de Grumetes, habilitarse y hacerse marineros hábiles" ${ }^{108}$.

Ese mismo año de 1778, en el que hubo en Madrid un importante movimiento contra la mendicidad abanderado por el propio rey a través del Consejo ${ }^{109}$, se crearon también allí las "Diputaciones de Caridad o de Barrio", compuestas de un alcalde de barrio, un eclesiástico, y tres vecinos honrados, con el objetivo de socorrer a los necesitados, y "recoger las limosnas fixas" de los vecinos, comunidades, cofradías, obras pías o conventos ${ }^{110}$. Paralelamente, surgió la "Junta General de Caridad”, compuesta por el gobernador de la Sala de Alcaldes, el corregidor, el vicario y visitador eclesiástico, un regidor del Ayuntamiento, un miembro del cabildo eclesiástico y otro de la Sociedad Económica de Madrid (que se había creado en la cercana fecha de 1775$)^{111}$. Todos ellos se encargarían de la administración de los fondos de la caridad en las distintas parroquias y de la gestión de los pobres ${ }^{112}$.

Junto a esta labor reformista llevada a cabo para el recogimiento de pobres en Madrid y Sitios Reales, el Consejo inició en la misma fecha otra más general para las ciudades del resto de España, abriendo un Expediente separado en el que se pedían a todas las Intendencias relaciones de las distintas cofradías y hermandades

IV, libro X, nn. 27, 34 y 41, pp. 2168-2170, 2178-2179, 2181-2184, y tomo IV, libro XI, nn. 84 y 85 , pp. 2349-2350.

${ }^{108}$ Véase Coronas GonzÁlez, S., El libro, cit. (n. 50), tomo IV, libro X, n. 27, p. 2169, y Nov. Rec. 7,39,18-20. El conjunto de las órdenes dadas ese año de 1778 para el recogimiento y destino de mendigos, puede consultarse también en la Colección de providencias, sobre recogimiento de Mendigos, y otros asuntos de policía, hecha de órden de la Sala de Señores Alcaldes de Casa y Corte de S. M., Madrid, 1790.

${ }^{109}$ Véase Vallejo García-Hevia, J.M., cit. (n. 17), pp. 129-130.

${ }^{110}$ Auto Acordado de 30 de marzo de 1778, en Nov. Rec. 7,39,22.

${ }^{111}$ Nov. Rec. 7,39,22, n. 16: "Cuidará la Diputación de informarse si en el distrito del barrio hay algunas cofradías ú obras pias aplicables á pobres; y pasará las noticias que adquiera al Secretario del Ayuntamiento, que lo sea de la Junta general establecida para formar las Congregaciones de caridad en las Parroquias".

${ }^{112}$ Véase Sempere y Guarinos, J., Policía, cit. (n. 15), pp. 132-134. 
que había en sus respectivas jurisdicciones, así como las cuentas relativas a los fondos que administraban, con la intención de proceder a crear, como en Madrid, un órgano público de gestión. Aunque al parecer no llegaron a tiempo todas las relaciones solicitadas, el Expediente terminó con la Real Cédula del Consejo de 3 de febrero de 1785, que extendía al resto de las capitales de provincia, corregimiento o partido, es decir, a las grandes ciudades de España, el contenido de los Autos Acordados dictados para Madrid, conminándolas a crear en ellas una Junta General de Caridad y Diputaciones de Barrio para arbitrar el socorro de pobres, siempre con la ayuda de los alcaldes de barrio ya nombrados ${ }^{113}$.

Las Diputaciones de Caridad se apoyaban, en consecuencia, en la anterior división administrativa efectuada en las grandes ciudades que se estructuraron en cuarteles y barrios diez años antes, a la que venía a completar. Y, aunque la autoría del proyecto se atribuyó por el propio rey a Floridablanca, lo cierto es que el mismo no hizo sino recoger una serie de propuestas que desde tiempo atrás estaban aireando distintos autores ilustrados, incluido el propio Campomanes ${ }^{114}$.

A partir de este momento, comenzó también lo que se ha calificado como "la misericordia asociada a la justicia", haciéndose un importante esfuerzo por parte del gobierno para aumentar los establecimientos públicos asistenciales que, al mismo tiempo, tenían un cierto carácter coactivo o penal, y servían al Estado para controlar a mendigos y vagos "ineptos". Con respecto a estos últimos, la Ordenanza de levas de 1775 había previsto meramente, de forma muy arbitraria, que "los vagos ineptos para las armas por defecto de talla ó de robustez, y los que no tengan la edad de diez y siete años, ó hayan pasado de la de treinta y seis, se deben recoger igualmente, $y$ dárseles destinos para el servicio de la armada, oficios, ó recogimiento en hospicios, y casas de misericordia ú otros equivalentes". Pero tales hospicios o casas de misericordia a los que entonces hacía referencia la ley, seguían siendo mayoritariamente los antiguos establecimientos privados de asistencia tradicional, a pesar de las numerosas críticas de los ilustrados.

Los hospicios o casas de misericordia tradicionales eran criticados, fundamentalmente, porque "erigidos en distintos tiempos, por distintas personas, de distintas ideas, y con principios y miras diferentes, no tienen entre si el sistema de unidad que debería tener para obrar con más actividad y producir más abundantes frutos" ${ }^{115}$. Frente a ellos, los pensadores iluministas proponían otro tipo de "hospicios generales", de carácter público y con una administración unitaria, en los que se separasen las distintas categorías de vagos ineptos y pobres verdaderos (niños, jóvenes, mujeres, ancianos, enfermos...), se fomentase el aprendizaje de un oficio y el trabajo en manufacturas, y se velase por la salud, el buen orden y la economía.

Los peligros de la asistencia tradicional y las nuevas propuestas de los " $m u$ chos Escritores políticos de la Nación”, fueron asumidas en 1769 por los Fiscales

\footnotetext{
${ }^{113}$ Nov. Rec. 7, 39, 22, nota 8. Atiéndase también a la Real Orden expedida el 25 de diciembre de 1780 para el recogimiento de mendigos, y socorro de los pobres respectivos á las Diputaciones de Caridad, en NoR. 7, 39, 23.

${ }^{114}$ Haciendo un estudio detallado de los escritos de Campomanes, así lo demuestra VALLejo García-Hevia, J.M., cit. (n. 17), pp. 132-137.

${ }^{115}$ Meléndez Valdés, J., Discursos, cit. (n. 45), p. 273.
} 
Campomanes y Moñino en su respuesta para la formación de una Hermandad de fomento de los Reales Hospicios de Madrid y San Fernando ${ }^{116}$. Y, finalmente, la Real Cédula sancionada por Carlos III en 1781 previó, por primera vez, la creación de unas llamadas "casas de recolección y enseñanza caritativa", que, no siendo aún los hospicios soñados por los ilustrados, albergaban un espíritu diferente al de los antiguos hospitales o casas de misericordia ${ }^{117}$.

La idea era que, mientras que se dotaban y construían los nuevos hospicios ${ }^{118}$, los vagos ineptos para el servicio de las armas quedaran al menos separados de los mendigos verdaderos, para facilitar la corrección y el cuidado de ambos grupos. Los que fueran menores de edad debían quedar en manos de los padres, o poderes públicos municipales si eran huérfanos, al objeto de "apartar de la mendiguez y de la ociosidad á toda la juventud, atajando el progreso y fuente perenne de la vagancia" 119 . Pero para los que fueran mayores de edad, se proponía una primera segregación de manera que, siendo pobres reales quedarían al cuidado de los hospicios y casas de misericordia existentes, y siendo vagos ineptos pasarían a ser custodiados en las nuevas casas de recolección y enseñanza caritativa, planteadas como una especie de presidios o lugares de depósito donde se dejaba a los delincuentes que no pudiesen servir al rey.

Ahora bien, debido a las dificultades económicas de mantener un doble sistema de casas para la pobreza, en 1784 se permitió que los vagos ineptos fueran enviados a las casas de misericordia o caridad con la única condición de que se les encerrase allí con carácter correctivo, y no asistencial, distinguiéndose claramente esta diferencia de cara al público. La medida provocó la inmediata reacción de los hospicios, que se quejaron ante el rey de recibir ese tipo de "personas viciosas de uno y otro sexo por via de corrección ó castigo", confundiéndose en la práctica con los pobres verdaderos; y Carlos III no tuvo más remedio que reiterar la separación entre pobreza verdadera y fingida en 1788, resolviendo que en adelante " $n o$ condenen de modo alguno á semejantes personas á las referidas casas ni aun por vía de depósito, no habiendo en ellas departamento de corrección" ${ }^{120}$.

Entre los aciertos de la política reformista debe apuntarse, no obstante, la campaña emprendida para la eliminación de obras pías, cofradías y pequeños hospitales, y la generalización de hospicios, como la institución típica del siglo XVIII para la educación y corrección de los pobres verdaderos. Entre 1760 y 1800 se crearon en España más de 50 hospicios o casas de reclusión para encerrar a los niños salidos de las Casas de Expósitos y a los mendigos capaces de traba-

${ }^{116}$ Publicada por Coronas González, S., Ilustración, cit. (n. 50), pp. 423-431, y El libro, cit. (n. 50), tomo III, libro VII, n. 18, pp. 1632-1638.

${ }^{117}$ Coronas González, S., El libro, cit. (n. 50), tomo IV, libro XII, n. 25, pp. 2435-2437, y Nov. Rec. 12,31,10.

${ }^{118}$ Véanse en este sentido los Informes de las Reales Sociedades Económicas de Madrid y Murcia (de 19 de febrero de 1781) sobre erección, dotación y gobierno de Hospicios o Casas de Misericordia, de orden del Consejo, en Coronas González, S., El libro, cit. (n. 50), IV, libro XII, n. 12, pp. 2401-2422.

${ }^{119}$ Nov. Rec. $12,31,10$.

${ }^{120}$ Nov. Rec. 12,40,19. En 1784, según consta en Nov. Rec. 12, 31, 12, se había reiterado el destino de vagos ineptos a los servicios convenientes de armas o marina. 
jar ${ }^{121}$. Según nos informa Trinidad Fernández, en el Diccionario de Canga de Argüelles se recoge ya la existencia de 101 hospicios en el año 1797, lo que nos demuestra el éxito del programa ilustrado en cuanto a la creación de este tipo de establecimientos $^{122}$.

Destacaron especialmente entre ellos algunos, como el Hospital de San Juan Bautista $^{123}$, o el Correccional de San Fernando, puesto en marcha por Pablo de Olavide tras el motín de Esquilache, que tanto Howard, cuando visitó España a finales del siglo XVIII, como Salillas, un siglo después, coincidieron en señalar como una verdadera casa de corrección en el que "delincuentes menores, vagos y pordioseros" acarreaban piedras a un horno de cal, lavaban o remendaban ropa, o hilaban hilo y estambre, en inmejorables condiciones ${ }^{124}$. Howard también destacó como establecimiento modelo el madrileño hospicio de la calle Fuencarral, en el que funcionaba una manufactura para el cardado e hilado de la lana ${ }^{125}$; y de todos fue reconocido el esfuerzo hecho por el padre Toribio en Sevilla para recoger y enseñar a los jóvenes en un establecimiento que recibió su propio nombre, los Toribios de Sevilla ${ }^{126}$. Pero téngase en cuenta que estas no fueron sino las excepciones, y que el proyecto ilustrado dejó todavía mucho por hacer en la dirección señalada.

[Recibido el 10 de mayo y aprobado el 2 de junio de 2009].

\section{BIBLIOGRAFÍA}

Alloza Aparicio, A., En busca de las causas del crimen. Teorías y estudios sobre delincuencia y justicia penal en la España Moderna, en Espacio, Tiempo y Forma, serie IV: Historia Moderna (2001), XIV.

Alonso, G. F. - Barral, M. E. - Fradkin, R. O. - Perri, G., Los vagos de la campana bonaerense: la construcción histórica de una figura delictiva (1730-1830), en Prohistoria (2001).

Alonso, G. F., El delito de vagancia durante el último cuarto del siglo XVIII, en Historias de la Ciudad. Una revista de Buenos Aires 11 (septiembre 2001).

Álvarez Santalo, L. C., La Casa de Expósitos de Sevilla en el siglo XVII (Madrid, 1977).

Antón Mellón, J., Ordenamiento jurídico burgués y cuestión social.

ANZANO, T. DE, Elementos preliminares para poder formar un sistema de gobierno de Hospicio general (Madrid, 1778).

Aranda, J., El Marqués de la Ensenada: estudios sobre su administración (Madrid, 1898).

${ }^{121}$ Carasa Soto, P., Los peligros, cit. (n. 12), pp. 433-435.

${ }^{122}$ Trinidad, P., Asistencia, cit. (n. 97), p. 44.

${ }^{123}$ Howard, J., El estado de las prisiones en Inglaterra y Gales (Londres, 1789, ed. cast. México, Fondo de Cultura Económica, 2003), p. 339.

${ }^{124}$ Howard, J., El estado, cit. (n. 123), pp. 340-342; y Salillas, R., Evolución penitenciaria de España (Madrid, 1919, ed. Pamplona, 1999), I, pp. 56-91.

${ }^{125}$ Howard, J., El estado, cit. (n. 123), p. 343.

${ }^{126}$ Sobre este establecimiento, véase: BACA, G., Los Toribios de Sevilla (Madrid, 1766). 
Arrazola, L., Enciclopedia española de Derecho y Administración, o Nuevo Teatro Universal de la Legislación de España e Indias (Madrid, 1849), II.

Arrom, S., Vagos y mendigos en la legislación mexicana (1745-1845), en Memoria del IV Congreso de Historia del Derecho Mexicano, (México, 1987), I.

BACA, G., Los Toribios de Sevilla (Madrid, 1766).

Bermúdez de Pedraza, Hospital Real de la Corte (Madrid, 1645).

Bernardo Ares, M., Las Ordenanzas municipales y la formación del Estado Moderno, en Axerquía. Revista de Estudios Cordobeses 6 (1983), en En la España medieval 3 (1987), y en El Poder Municipal y la Organización Politica de la Sociedad (Córdoba, 1998).

Callaban, W., The Problema of Confinement: An Aspect of Por Relief in Eighteenth Century Spain, en Hispania American Historical Review 51 (febrero, 1971) 1.

Campillo y Cossío, J. del, Dos escritos políticos. Lo que hay de más y de menos en España para que sea lo que debe ser y no lo que es. España despierta (ed. Oviedo, 1993).

Campomanes, P. R. de, Discurso sobre el fomento de la industria popular (Madrid, 1774, ed. Instituto Estudios Fiscales, Madrid, 1975).

Capellán de Miguel, G., Enciclopedia del pauperismo (Cuenca, 2007), 5 vols.

CARASA Soto, P., Los peligros de la pobreza. Los valores del liberalismo y las soluciones asistenciales burguesas, en Antiguo Régimen y liberalismo. Homenaje a Miguel Artola (Madrid, 1995), II.

Carasa Soto, P., Pauperismo y Revolución burguesa. Burgos 1750-1900 (Valladolid, 1987).

Caridad discreta practicada con los mendigos, y utilidades que logra la República en su recogimiento (Valladolid, 1757).

Colección de providencias, sobre recogimiento de Mendigos, y otros asuntos de policia, hecha de órden de la Sala de Señores Alcaldes de Casa y Corte de S. M. (Madrid, 1790).

Coronas González, S., El libro de las leyes del siglo XVIII, (Madrid, 1996), 5 vols.

Coronas González, S., Ilustración y derecho. Los fiscales del Consejo de Castilla en el siglo XVIII (Madrid, 1992).

Coronas, C. E. - Armillas, J. A., La España de las reformas (Madrid, 1989).

Corral García, E., Ordenanzas de los concejos castellanos: formación, contenido y manifestación. Siglos XIII-XVIII (Burgos, 1988).

Cortes de los Antiguos Reinos de León y Castilla (Madrid, 1863).

Dou y Bassols, R.L., Instituciones del Derecho público general de España con noticia del particular de Cataluña (1742-1832) (ed. Barcelona, 1975).

Durkheim, E., Suicide. A Study in Sociology (1897, New York, 1951).

Dym, J., La policía de Nueva Guatemala: la disputa de los alcaldes de barrio, en el VII Congreso de Historia Centroamericana (Tegucigalpa, Honduras, julio 2004).

Egido López, T., La expulsión de los jesuitas de España, en Historia de la Iglesia en España, (Madrid, 1979), IV.

Embid Irujo, A., Ordenanzas y reglamentos municipales en el Derecho español (Madrid, 1978).

Ferrer Benimelli, J. A., Don Ramón Pignatelli y el motín de Esquilache: una nueva versión del motín de Zaragoza, en Actas del I Symposium del Seminario de Instrucción Aragonesa (Zaragoza, 1987).

Foucault, M., Historia de la locura (México, 1979).

Foucault, M., Vigilar y castigar (ed. Madrid, 1992). 
Franco Silva, A., Estudios sobre ordenanzas municipales (siglos XIV-XVI) (Cádiz, 1999).

Galdiano y Croy, L., Breve tratado de los hospitales y casas de recogimiento desta Corte (Madrid, 1677).

GiginTA, M., Tractado del remedio de pobres (Coimbra, 1579).

Giménez López, E., Militares en Valencia (1707-1808). Los instrumentos del poder borbónico entre la Nueva Planta y la crisis del Antiguo Régimen (Alicante, 1990).

Gómez Ruiz, T., El Hospital Real de Santa María Magdalena y la Casa de Expósitos de Almería (Almería, 1997).

Gómez UrdáN̄Ez, J. L., El proyecto reformista del Marqués de Ensenada (Logroño, 2008).

Guillamón, J., Las reformas de la administración durante el reinado de Carlos III (Un estudio sobre dos reformas administrativas de Carlos III) (Madrid, 1980).

HOWARD, J., El estado de las prisiones en Inglaterra y Gales (Londres, 1789, ed. cast. México, Fondo de Cultura Económica, 2003).

Jiménez Salas, M., Historia de las asistencia social en la España Moderna (Madrid, 1958); o TrINIDAD, P., Asistencia y previsión social en el siglo XVIII, en AAVV, De la beneficencia al bienestar social: cuatro siglos de acción social (Madrid, 1986).

Jones, M., La Contrarreforma: Religión y sociedad en la Europa moderna (trad. cast., Madrid, Akal, 2003).

Jovellanos, G. M., Discurso acerca de la situación y división interior de los hospicios con respecto á su salubridad, en Obras, V.

Jovellanos, G. M., Discurso que pronunció en la Sociedad Económica de Madrid en 24 de diciembre de 1784, en Obras (Madrid, BAE, 1952), II.

Ladero Quesada, M. A., Las ordenanzas locales (siglos XIII-XVIII), en En la España Medieval 21 (1998).

López Alonso, C., La pobreza en la España medieval. Estudio Histórico-Social (Madrid, 1986).

Macías Delgado, J., El motín de Esquilache a la luz de los documentos (Madrid, 1988).

Martín Gamero, A., Ordenanzas para el buen régimen y gobierno de la muy noble, muy leal e imperial ciudad de Toledo (Madrid, 1998, recurso electrónico, Fundación Histórica Tavera).

Meléndez Valdés, J., Discursos forenses, en Obras Completas (Madrid, Biblioteca Castro, 1997), III.

Melossi, D. - Pavarini, M., Cárcel y fábrica. Los origenes del sistema penitenciario (siglos XVI-XIX) (trad. cast. México, 1985).

Murcia, P. J., Discurso político sobre la importancia y necesidad de los hospicios, casas de expósitos y hospitales (Madrid, 1798).

NiCÉFORO, A., La transformación del delito en la sociedad moderna (Madrid, 1902, trad. de C. Bernaldo de Quirós).

Nueva Recopilación

OyARZÁBAL, G. A., La Armada española y el gobierno de Río de la Plata: aspectos formales e informales de una compleja relación (1760-1800), en $49^{\circ}$ Congreso Internacional de Americanistas (Quito, 1997).

Palop Ramos, J. M., Delitos y penas en la España del siglo XVIII, en Estudis 22 (1996).

Pasukanis, E. B., Teoría general del Derecho y el marxismo (Barcelona, 1976). 
PaVArini, M., Control y dominación. Teorías criminológicas burguesas y proyecto hegemónico (Buenos Aires, 2003).

Pérez de Herrera, C., Discurso del Amparo de los legitimos pobres y reducción de los fingidos (Madrid, 1598, Madrid, Clásicos Castellanos, 1975).

Pérez Estévez, R., El problema de los vagos en la España del siglo XVIII (Madrid, 1976).

Perrotta, C., La disputa sobre los pobres en los siglos XVI y XVII: España entre desarrollo y regresión, en Cuadernos de Ciencias Económicas y Empresariales (1999).

Ramos VÁzQUEZ, I., "De meretricia turpidine”. Una visión jurídica de la prostitución en la Edad Moderna castellana (Málaga, 2005).

Real Ordenanza de vagos de 30 de abril de 1745, en Pérez y López, A. X., Teatro de la legislación universal de España en Indias, por orden cronológico de sus cuerpos y decisiones no recopiladas (Madrid, 1797), p. 443.

RECANSENS I BRUNET, A., La burguesía y los orígenes del aparato policial, en BERGALLI, R. - MARI, E., Historia ideológica del control social (Barcelona, 1989).

Roldán Barbero, H., Historia de la prisión en España (Barcelona, 1988).

Salillas, R., Evolución penitenciaria de España (Madrid, 1919, ed. Pamplona, 1999), I, pp. 56-91.

Santolaria Sierra, F., Marginación y educación. Historia de la educación social en la España moderna y contemporánea (Barcelona, 1997).

Sempere y Guarinos, J., Biblioteca Española Económico-Politica (Madrid, 1801), I.

Sempere y Guarinos, J., Policía de España acerca de los pobres, vagos y malentretenidos, en Biblioteca, cit. (n. 13), I.

Soly, H., Pobreza y capitalismo en la Europa preindustrial (1350-1850) (Madrid, 1986).

Soто, D., Deliberación en la causa de los pobres (Salamanca, 1545; edición de Martínez Casado, E., La causa de pobres, Salamanca, 2006).

Soubeyroux, J., El encuentro del pobre y la sociedad: asistencia y represión en el Madrid del siglo XVIII, en Estudios de Historia Social 20-21 (1982).

Summer, C., Marxism and Deviancy Theory, en The Sociology of Crime and Delinquency (The New Criminologies) (New York, 1976).

Susín Beltrán, R., Los discursos sobre la pobreza. Siglos XVI-XVIII, en Cuadernos de Investigación Histórica Brocar 24 (2000).

Trinidad Fernández, P., La defensa de la sociedad. Cárcel y delincuencia en España (siglos XVIII-XX) (Madrid, 1991).

TRINIDAD, P., Asistencia y previsión social en el siglo XVIII, en AA. VV, De la beneficencia al bienestar social: cuatro siglos de acción social (Madrid, 1986).

Tuero Bertrand, F., Alcaldes de cuartel, alcaldes de barrio y autos de buen gobierno en el Oviedo del siglo XVIII, en el Boletín del Instituto de Estudios Asturianos 80 (Oviedo, 1973).

Vallejo García-Hevia, J. M., Campomanes y la acción administrativa de la Corona (1762-1802) (Oviedo, 1998).

VelázQuez, M., Desigualdad, indigencia y marginación social en la España ilustrada: las cinco clases de pobres de Pedro Rodríguez Campomanes (Murcia, 1991).

Vidal Gavidia, M. A., La Casa de Arrepentidas de Valencia (Valencia, 2001).

VIVES, Juan Luis, Tratado del socorro de los pobres (Brujas, 1526, trad. cast. de J. G.

Nieto, Valencia, s.f.). 
Ward, B., Obra Pía. Medio de remediar la miseria de la gente pobre de España, en Proyecto [véase], p. 196.

Ward, B., Proyecto económico (Madrid, 1762, ed. L. Castellano, Madrid, 1982). 